\title{
Prevalência e fatores associados às alterações neurocognitivas em adultos infectados com HIV-1 via transmissão vertical
}

Dissertação apresentada à Faculdade de Medicina da Universidade de São Paulo para a obtenção do título de Mestre em Ciências.

Programa de Doenças Infecciosas e Parasitárias Orientador: José Ernesto Vidal Bermúdez

SÃO PAULO

2018 


\section{Dados Internacionais de Catalogação na Publicação (CIP)}

Preparada pela Biblioteca da

Faculdade de Medicina da Universidade de São Paulo

Creproduçăo autorizada pelo autor

Silvany, Sarah Moura

Prevalência e fatores associados às alteraçöes neurocognitivas em adultos infectados com HIV-1 via transmissão vertical / Sarah Moura Silvany, -. Săo Paulo, 2018.

Dissertaçāo (mestrado) - Faculdade de Medicina da Universidade de são paulo.

Programa de Doenças Infecciosas e Parasitárias.

Orientador: José Ernesto Vidal Bermúdez.

Descritores: 1.HIV 2.Sindrome de imunodeficiência adquirida 3, Transtornos neurocognitivos 4.Adulto

5.Transmissão vertical de doença infecciosa 6. Brasil

USP/FM/DBD- $492 / 18$

Responsável: Erinalva da Conceição Batista, CRB-8 6755 


\section{DEDICATÓRIA}

Aos pacientes do SEAP que confiaram em meu trabalho e compartilharam comigo não somente informações que eram necessárias para a elaboração desse trabalho, mas histórias de uma vida. A partir de vocês pude evoluir como profissional e como pessoa.

Ao meu avô (in memoriam), uma de minhas grandes referencias e maior incentivador da minha carreira acadêmica.

A minha avó, que desde cedo, através de suas ricas e prazerosas conversas, me mostrou a importância do aprendizado em todas as suas formas.

Ao meu pai (in memoriam), perder você durante esse processo foi difícil. Saber que desejaria que eu finalizasse esse projeto me fez ir até o fim.

A minha mãe, meu maior exemplo de ser humano e de profissional. Sua resiliência, fé e boa energia foram o combustível para eu chegar até aqui e para que eu siga em frente. 


\section{AGRADECIMENTOS}

Ao meu orientador Prof. José Ernesto Vidal Bermúdez, por sua contribuição, compreensão e seu apoio na realização desta pesquisa.

A Dra. Maria Rita Polo Gascón, que desde o início da minha trajetória em São Paulo se tornou o meu norte e o meu porto seguro. Fonte inesgotável de conhecimento e de empatia, você tem toda a minha admiração e respeito, sem você este trabalho não teria sido realizado.

Ao programa de Programa de Pós-Graduação em Doenças Infecciosas e Parasitárias da FMUSP, pelos ensinamentos e suporte financeiro a esta pesquisa. Em especial a Roseli Antonia Santo, quando eu ainda não era aluna da pós compartilhou comigo parte de sua longa e admirável trajetória dentro da MI. Obrigada por toda atenção, compreensão e paciência com a qual lidou comigo durante esses anos.

A toda equipe multiprofissional do SEAP, pela disponibilidade e acolhimento. Um agradecimento especial a enfermeira Camila Picone que desde o inicio desse estudo, de maneira acolhedora, se colocou completamente disponível para me ajudar em tudo que fosse possível e assim o fez.

Aos meus amigos, em especial a Fernanda Bastos, Luiza Becher e Mayra Lima, obrigada pelas contribuições e suporte quando precisei de vocês nesses últimos anos.

Obrigada. 
Esta dissertação está de acordo com as seguintes normas, em vigor no momento desta publicação:

Referências: adaptado de International Committee of Medical Journals Editors (Vancouver).

Universidade de São Paulo. Faculdade de Medicina. Divisão de Biblioteca e Documentação. Guia de apresentação de dissertações, teses e monografias. Elaborado por Anneliese Carneiro da Cunha, Maria Julia de A. L. Freddi, Maria F. Crestana, Marinalva de Souza Aragão, Suely Campos Cardoso, Valéria Vilhena. 3a ed. São Paulo: Divisão de Biblioteca e Documentação; 2011.

Abreviaturas dos títulos dos periódicos de acordo com List of Journals Indexed in Index Medicus. 


\section{Sumário}

Lista de Siglas e Abreviações

Lista de Tabelas

Lista de Figuras

Lista de gráficos

Resumo

Abstract

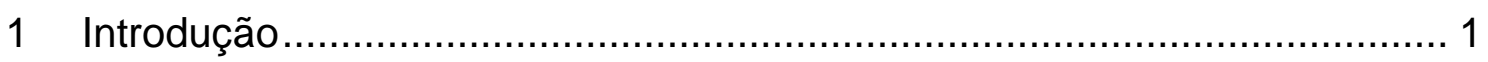

1.1 Epidemiologia da infecção pelo HIV -1 ............................................ 1

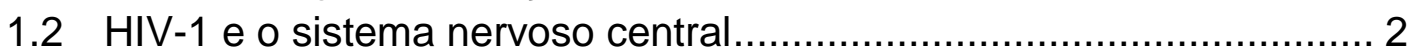

1.3 Tratamento Antirretroviral e HAND ................................................... 7

2 Justificativa do Estudo ...................................................................... 10

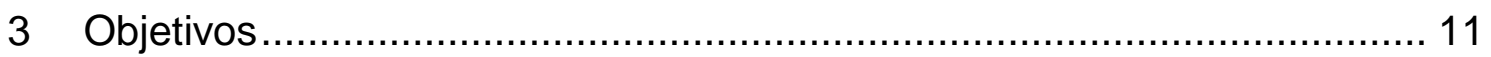

3.1 Objetivo principal ....................................................................... 11

3.2 Objetivos secundários: ............................................................. 11

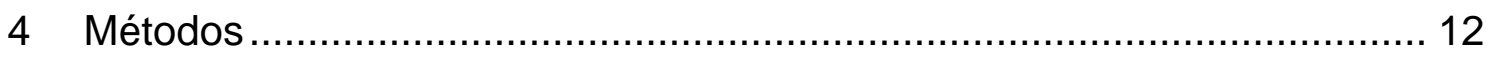

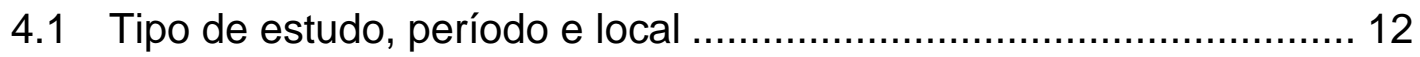

4.2 Critérios de inclusão e exclusão ………………........................... 12

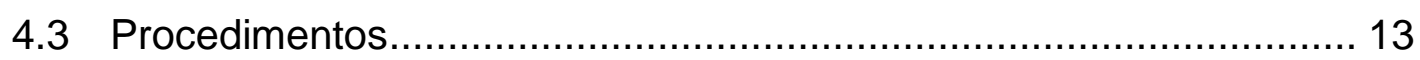

4.4 Instrumentos .......................................................................... 13

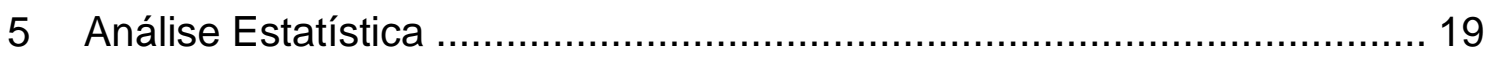

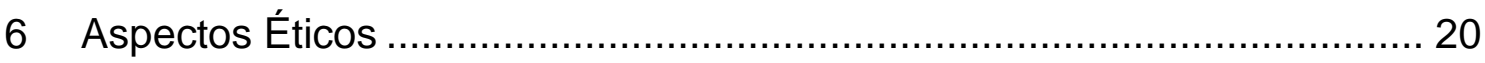

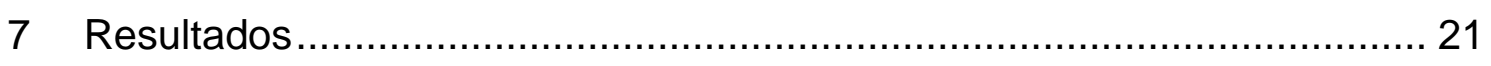

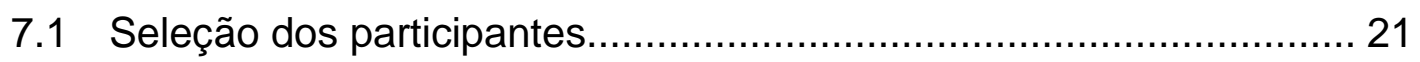

7.2 Dados demográficos e gerais do população estudada...................... 21

7.3 Frequência de HAND em adultos infectados pelo HIV-1 via

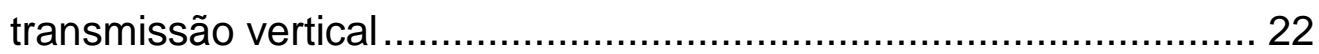

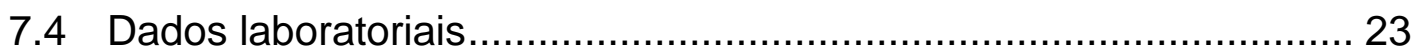

7.5 Frequência de ansiedade/depressão em adultos infectados pelo HIV-1 via transmissão vertical ...................................................... 25

7.6 Avaliação do questionário neuropsicológico breve ........................... 25

7.7 Avaliação neuropsicológica por domínios neurocognitivos................... 26 


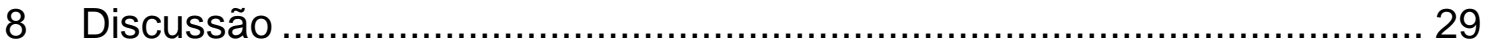

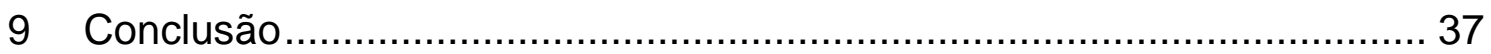

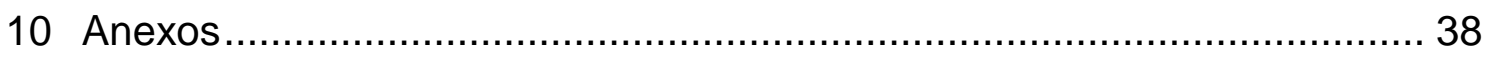

Anexo A - Dados Demográficos e Clínicos ........................................... 38

Anexo B - ASSIST - Questionário para Triagem do Uso de Álcool, Tabaco e Outras Substâncias................................................................. 39

Anexo C - HAD - Escala de Depressão e Ansiedade Hospitalar............... 44

Anexo D - Questionário Neurocognitivo Breve...................................... 46

Anexo E - Escala Instrumental para Atividades da Vida Diária Lawton.

Adaptado de: Lopes dos Santos e Virtuoso Junior, 2008. ....................... 47

ANEXO F - International HIV Dementia Scale. Adaptado de: Sackor e

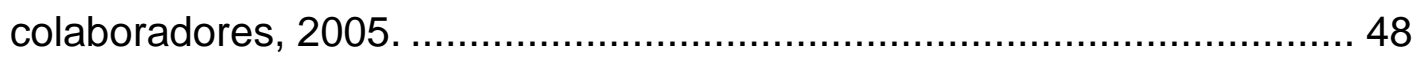

ANEXO G - Trail Making Test A and B ……...................................... 50

ANEXO H - Termo de Consentimento Livre e Esclarecido (TCLE) ............... 54

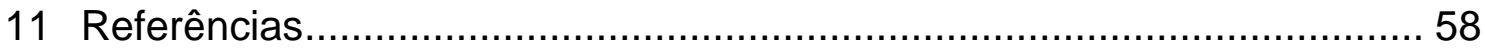




\section{Lista de Siglas e Abreviações}

aids: $\quad$ Acquired Immune Deficiency Syndrome

ANCOVA: Analysis of Covariance

ANI: $\quad$ Asymptomatic Neurocognitive Impairment

ANOVA: $\quad$ Analysis of Variance

ASSIST: $\quad$ Alcohol, Smoking and Substance Involvement Screening Test

BHE: $\quad$ Barreira Hemato-Encefálica

CD4: $\quad$ Cluster of Differentation 4

CEAT: $\quad$ Cuestionario para la Evaluación de la Adhesión al Tratamiento Antiretroviral

CPE: $\quad$ CNS Penetration-Effectiveness

HAART: Highly Active Antiretroviral Therapy

HAD: $\quad$ HIV Associated Dementia

HADS: $\quad$ Hospital Anxiety and Depression Scale

HAND: $\quad$ HIV Associated Neurocognitive Disorders

HCFMUSP: Hospital das Clínicas da Faculdade de Medicina da Universidade de São Paulo

HDL: $\quad$ High-Density Lipoprotein Cholesterol

HIV: $\quad$ Human Immunodeficiency Virus

IHDS: $\quad$ International HIV Dementia Scale

LDL: $\quad$ Low-Density Lipoprotein Cholesterol

MND: $\quad$ Mild Neurocognitive Disorder

OMS: $\quad$ Organização Mundial de Saúde

PVHIV: $\quad$ Pessoas Vivendo com HIV

RAVLT: $\quad$ The Rey Auditory-Verbal Learning Test

SNC: $\quad$ Sistema Nervoso Central

TARV: $\quad$ Terapia Altamente Eficaz com Antirretrovirais

TCLE: $\quad$ Termo de Consentimento Livre e Esclarecido

WAIS III: Escala de Inteligência para Adultos

VLDL: $\quad$ Very Low Density Lipoprotein 


\section{Lista de Tabelas}

Tabela 1. Distribuição dos pacientes adultos infectados pelo HIV-1 via transmissão vertical sem alteração neurocognitiva, ANI, MND, e HAD, segundo características sociodemográficas.

Tabela 2: Distribuição dos dados laboratoriais de pacientes adultos infectados pelo HIV-1 via transmissão vertical, de acordo com as categorias HAND

Tabela 3. Frequência de Depressão e Ansiedade em pacientes adultos portadores de HIV-1 infectados via transmissão vertical de acordo com as classificações de HAND

Tabela 4. Questionário Neurocognitivo Breve dos pacientes adultos portadores de HIV-1 infectados via transmissão vertical avaliados através das categorias HAND: resultados baseados no autorrelato dos pacientes ...... 26

Tabela 5. Distribuição da performance cognitiva dos pacientes adultos, infectados pelo HIV-1 via transmissão vertical, na bateria neuropsicológica, de acordo com a classificação de HAND

Tabela 6. Distribuição da performance cognitiva dos pacientes adultos, infectados pelo HIV-1 via transmissão vertical, nas Escalas de Rastreio de HAND e de AVDs, de acordo com a classificação de HAND 


\section{Lista de Figuras}

Figura 1. Fluxograma dos pacientes entrevistados e incluídos na amostra .... 21 


\section{Lista de Gráficos}

Gráfico 1. Frequência das alterações neurocognitivas associadas ao HIV-1 em adultos infectados pelo HIV-1 via transmissão vertical. . 


\section{Resumo}

Silvany SM. Prevalência e fatores associados às alterações neurocognitivas em adultos infectados com HIV-1 via transmissão vertical [dissertação]. São Paulo: Faculdade de Medicina, Universidade de São Paulo; 2018

As alterações neurocognitivas associadas ao HIV-1 (HAND) são frequentes em adultos infectados pelo HIV-1 via transmissão sexual. Existe pouca informação sobre HAND em adultos infectados pelo HIV-1 via transmissão vertical. Este estudo teve como objetivos identificar a prevalência das HAND em adultos infectados por transmissão vertical assim como identificar a prevalência de depressão nessa população. Pacientes e métodos: trata-se de um estudo de delineamento transversal, realizado entre janeiro 2016 e maio de 2017, no Serviço de Extensão ao Atendimento de Pacientes HIV/aids (SEAP) da Divisão de Moléstias Infecciosas e Parasitárias do Hospital das Clínicas, Faculdade de Medicina da Universidade de São Paulo. O SEAP é um serviço exclusivamente ambulatorial, localizado na cidade de São Paulo. Os critérios de inclusão foram: (i) pacientes com diagnóstico de infecção pelo HIV-1 por transmissão vertical; (ii) idade igual ou superior a 18 anos; (iii) escolaridade mínima de 4 anos; e (iv) consentimento para participar do estudo. Os critérios de exclusão foram: (i) diagnóstico concomitante de doenças neurológicas oportunistas ou condições neurológicas, previamente documentadas; (ii) uso de substâncias psicoativas; (iii) incapacidade física para aplicação dos testes, (iv) recusa da assinatura do Termo de Consentimento Livre e Esclarecido. Foram utilizados como instrumentos de pesquisa: questionário sociodemográfico, escala de ansiedade e depressão hospitalar, escala de atividades de vida diária de Lawton e bateria neuropsicológica formal. Para análise estatística foram calculadas frequência, média e desvio padrão, assim como testes qui-quadrado, anova e análise posthoc. Valores de $p<0.05$ foram considerados estatisticamente significativos. Foi utilizado o programa SPSS 21.0. Resultados: foram avaliados 28 participantes: $15(53.6 \%)$ foram do sexo feminino e a idade média e o desvio padrão (DP) foi de 22 (6.7) anos. Foi identificado HAND em 23 (82,1\%) pacientes: 12 (42.9\%) tiveram alteração neurocognitiva assintomática (ANI), 6 (21,4\%) tiveram comprometimento neurocognitivo leve (MND) e 5 (17.9\%) tiveram demência associada ao HIV-1 (HAD). A atenção, velocidade de processamento e velocidade motora foram as funções cognitivas mais comprometidas. $3(10.7 \%)$ pacientes apresentaram depressão; $3(60 \%)$ dos 5 pacientes com HAD apresentaram depressão. Conclusões: neste estudo encontramos elevada prevalência de HAND em adultos infectados pelo HIV-1 via transmissão vertical, chamando atenção também a elevada proporção de pacientes com HAD. Por outro lado, identificamos baixa prevalência de depressão na população total do estudo, mas a prevalência de depressão foi elevada dentre os pacientes com HAD.

Descritores: HIV; síndrome de imunodeficiência adquirida; transtornos neurocognitivos; adulto; transmissão vertical de doença infecciosa; Brasil. 


\begin{abstract}
Silvany SM. Prevalence and associated factors with neurocognitive disorders in adults vertically infected with HIV-1 [dissertation]. São Paulo: "Faculdade de Medicina, Universidade de São Paulo"; 2018

Neurocognitive disorders associated with HIV-1 (HAND) are common in adults sexually infected with HIV-1. There is little information about HAND in adults vertically infected with HIV-1. This study aimed to identify the prevalence of HAND in adults vertically infected with HIV-1 as well as to identify the prevalence of depression in this population. Patients and methods: This is a cross-sectional study, conducted between January 2016 and May 2017, at the Extension Service for HIV/aids Patients (SEAP) of the Division of Infectious and Parasitic Diseases of the Hospital das Clínicas of University of São Paulo Medical School. SEAP is an exclusively outpatient service, located in the city of São Paulo. Inclusion criteria were: (i) patients diagnosed with HIV-1 infected by vertical transmission; (ii) age equal to or more than 18 years; (iii) minimum schooling of 4 years; and (iv) consent to participate in the study. Exclusion criteria were: (i) concomitant diagnosis of opportunistic neurological diseases or neurological conditions, previously documented; (ii) use of psychoactive substances; (iii) physical incapacity to apply the tests, (iv) refusal to sign the Free and Informed Consent Form. The following research assessment tools were used: sociodemographic questionnaire, hospital anxiety and depression scale, Lawton daily life activity scale and formal neuropsychological battery. For statistical analysis, we calculated frequency, mean and standard deviation, as well as chi-square, anova and post-hoc analysis. Values of $p<0.05$ were considered statistically significant. The SPSS 21.0 program was used. Results: 28 participants were evaluated: 15 (53.6\%) were female and the mean age and standard deviation (SD) were 22 (6.7) years. HAND was identified in $23(82.1 \%)$ patients: 12 (42.9\%) had asymptomatic neurocognitive impairment (ANI), 6 (21.4\%) had mild neurocognitive impairment and 5 (17.9\%) had dementia associated with HIV-1 (HAD). Attention, processing speed and motor speed were the most compromised cognitive functions. 3 $(10.7 \%)$ patients presented depression; $3(60 \%)$ of the 5 patients with HAD had depression. Conclusions: in this study we found a high prevalence of HAND in adults vertically infected, also calling attention to the high proportion of patients with HAD. On the other hand, we identified a low prevalence of depression in the total study population, but the prevalence of depression was high among patients with HAD.
\end{abstract}

Descriptors: HIV; acquired immunodeficiency syndrome; neurocognitive disorders; adult; infectious disease transmission, vertical; Brazil. 


\section{Introdução}

\subsection{Epidemiologia da infecção pelo HIV-1}

A síndrome de imunodeficiência adquirida (aids) constitui a manifestação clínica mais grave da infecção crônica e progressiva, causada pelo vírus de imunodeficiência humana tipo 1 (HIV-1), caracterizando-se pela baixa contagem de linfócitos T- CD4+.

Em junho de 1981 foram notificados pelo Centro de Controle e Prevenção de Doenças (CDC) dos Estados Unidos da América, cinco pacientes do sexo masculino e homossexuais que apresentavam infecções oportunistas raramente vistas, e que na época foram associadas a pessoas com deficiência da imunidade celular ${ }^{1}$. Esses foram os primeiros casos do que posteriormente se denominaria como aids. Depois de se identificar a transmissão sexual, não passou muito tempo para reconhecer a transmissão vertical e a transmissão através de sangue infectado (mediante transfusões ou pelo compartilhamento de agulhas em usuários de drogas endovenosas). No Brasil, em 1982, os dois primeiros casos de aids foram identificados pela dermatologista Valéria Petri, da Escola Paulista de Medicina ${ }^{2}$. Segundo dados do Ministério da Saúde, o primeiro caso de transmissão vertical do HIV no Brasil, foi notificado em $1985^{3}$, sendo que, nessa época, os bebês infectados não tinham expectativas de controle terapêutico. Desde então a infecção pelo HIV-1 constitui um sério problema de saúde pública, principalmente em países de baixa e média renda.

De acordo com as estimativas realizadas pela Organização Mundial da Saúde $^{4}$ (2016), existem 36,7 milhões de pessoas vivendo com o HIV-1 (PVHIV). Desse total, aproximadamente, 34,5 milhões são adultos (homens: 16,7 milhões; mulheres: 17,8 milhões) e 2,1 milhões são crianças ( $<15$ anos). No ano de 2016 foram diagnosticados 1,8 milhões de novos casos e, 
aproximadamente e 1 milhão de pessoas faleceram no estágio mais avançado da infecção ${ }^{4}$

O relatório recente do Programa Conjunto das Nações Unidas sobre HIV/AIDS (UNAIDS), estima que, no Brasil, havia 830.000 [610.000 1.100.000] PVHIV em 2015. Nesse mesmo ano, 44.000 [32.000 - 59.000] pessoas foram infectadas pelo HIV-1. Estima-se que a prevalência dessa infecção no Brasil oscila entre 0,4\% a 0,7\% em pessoas de 15 a 49 anos $^{5}$. No Brasil, foi identificado que a infecção tem maior prevalência em indivíduos com idade entre 25 e 39 anos, para ambos os sexos, com destaque para o aumento da incidência entre os jovens de 15 a 24 anos (No Brasil, 84\% dos casos de aids diagnosticadas em crianças foram atribuídos à transmissão vertical ${ }^{6}$.

A transmissão vertical é um termo que se refere à infecção da criança através da mãe, no útero, durante o processo de nascimento ou por meio da amamentação. Desses três componentes, a passagem do neonato pelo canal do parto é o componente mais crítico. A introdução da terapia antirretroviral altamente ativa (HAART, do inglês highly active antirretroviral therapy) mudou significativamente as taxas de sobrevida e a qualidade de vida de todas as populações de PVHIV, incluindo no caso de crianças com infecções por HIV ${ }^{7}$. Essas e outras mudanças proporcionadas pelo a introdução do tratamento medicamentoso têm possibilitado a redução progressiva do número de crianças infectadas pelo HIV-1 e o prolongamento da expectativa de vida de crianças e adolescentes infectados pelo HIV $-1^{8}$. Contudo, PVHIV dessas faixas etárias, apresentam particularidades que requerem uma abordagem especial e diferenciada.

\subsection{HIV-1 e o sistema nervoso central}

O sistema nervoso central (SNC) é um dos locais mais comumente comprometidos pelo HIV-1. O vírus se caracteriza por ser neurotrópico e infecta o cérebro poucos dias depois da infecção aguda. O HIV-1 atravessa a barreira hemato-encefálica através de macrófagos infectados, mediante o mecanismo denominado "cavalo de Tróia". Dessa forma, se instala no cérebro, um dos 
seus principais "santuários" "Uma vez instalado no cérebro, o vírus infecta células gliais que, em última instância, secretam neurotoxinas que podem levar ao dano e morte neuronal, mesmo que o HIV-1 não infecte efetivamente os neurônios $^{10}$. A infecção ativa, persistente e continua, causada pelo HIV-1, permite a manutenção de dois processos que atuam sinergicamente para deteriorar as funções cerebrais: inflamação e imunoativação celular. Foi identificada perda neuronal sobre todo córtex frontal, atrofia cerebral e desmielinização, fundamentalmente nas zonas periventriculares, corpo caloso, cápsula interna, comissura anterior e trato óptico ${ }^{11,12}$ (Exames de necropsia de pacientes infectadas pelo HIV-1 mostraram a presença de vírus em estruturas corticais, como lobos frontais, substância branca subcortical e gânglios basais ${ }^{13}$

As alterações decorrentes da presença do HIV-1 no SNC, podem ser classificadas de várias formas: 1) a partir da topografia comprometida: SNC ou o sistema nervoso periférico (SNP); 2) a partir do estágio clínico-imunológico da infecção pelo HIV-1: se acontece no momento da soroconversão, na infecção crônica ("fase de latência clínica"), ou na fase tardia, na qual existe imunossupressão significativa; e 3) a partir da etiologia: doenças primárias ou diretamente relacionadas com o HIV-1, e as doenças secundárias, causadas por doenças oportunistas (infecciosas ou neoplásicas), favorecidas pela imunossupressão ${ }^{14,15}$.

O espectro de manifestações neurológicas primárias é amplo, e dentre elas estão as alterações neurocognitivas, denominadas como alterações neurocognitivas associadas ao HIV (HIV-associated neurocognitive disorders, HAND). As formas mais graves das mesmas se caracterizam pela presença de manifestações neurocognitivas e comportamentais que impactam negativamente nas atividades cotidianas ${ }^{26,27}$. No início da epidemia, as alterações neurocognitivas mais graves foram precocemente reconhecidas e caracterizadas do ponto de vista neuropatológico e clinico ${ }^{16}$. Posteriormente, foram se conhecendo e estudando manifestações neurocognitivas menos graves, mesmo em indivíduos que fazem o uso regular do $\mathrm{HAART}^{17,18}$. Atualmente, estima-se que entre $15 \%$ a $50 \%$ dos adultos infectados pelo HIV-1, apresentam algum grau de alteração cognitiva associada ao HIV. As frequências variáveis dependem das características da população estudada (por exemplo, idade) e dos métodos 
usados para avaliar o comprometimento neurocognitivo (por exemplo, uso de bateria neuropsicológica formal) (Nightingale $S$ et al. Controversies in HIVassociated neurocognitive disorders). ${ }^{19.20 .21 .22}$.

No Brasil, alguns estudos realizados em pacientes ambulatoriais têm avaliado a prevalência das HAND, com resultados variáveis, entre 30-74\% (Em contraste, estudo realizado com pacientes internados, relatou prevalência de $5 \%$ de demência associada ao HIV, entre pacientes internados devido a doenças neurológicas ${ }^{23,24,25}$.

A elevada prevalência das HAND reforça a necessidade de que as funções neurocognitivas sejam regularmente avaliadas em PVHIV, inclusive naquelas sem queixas espontâneas. As HAND podem interferir na qualidade de vida do paciente, prejudicar suas funções laborativas bem como incidir de forma negativa na adesão ao tratamento ${ }^{26,27}$.

A classificação atual das alterações neurocognitivas está de acordo com os critérios da Academia Americana de Neurologia, também conhecido como Critérios de Frascati ${ }^{28}$. As pessoas são classificadas de acordo com o aumento da severidade das alterações cognitivas, excluindo a possibilidade de correlação com comorbidades:

- Alteração Neurocognitiva Assintomática (ANI, asymptomatic neurocognitive impairment): há alterações de $\geq 2$ domínios cognitivos, em pelo menos um desvio padrão abaixo da média na avaliação e sem impacto nas atividades de vida diária;

- Comprometimento Neurocognitivo Leve (MND, mild neurocognitive disorder): há alterações de $\geq 2$ domínios cognitivos em pelo menos um desvio padrão abaixo da média na avaliação neuropsicológica e com comprometimento leve nas atividades de vida diária;

- Demência Associada ao HIV (HAD, HIV-associated dementia): há alterações graves de $\geq 2$ domínios cognitivos, geralmente o distúrbio é encontrado em múltiplos domínios, especialmente no aprendizado de novas informações, alentecimento no processamento de novas informações e déficit em atenção e concentração e com comprometimento significativo nas atividades de vida diária. 
No curso da infecção pelo HIV o vírus ao entrar no SNC poderá comprometer de maneira progressiva, e de forma e tempo variável, as esferas cognitiva, comportamental e motora, características que são pertinentes às demências subcorticais ${ }^{14,29,30}$. Nas primeiras fases, nas quais as alterações neurocognitivas começam a se manifestar, os sinais/sintomas são leves, incluindo déficit de memória, alentecimento na velocidade do processamento mental, perda da capacidade de concentração, apatia, perda de interesse no trabalho e nas atividades de lazer ${ }^{31}$. Nesse período, que abarca os quadros sintomáticos leves e moderados, os sintomas/sinais ainda são discretos, quando comparados aos mais graves, e podem permanecer estáveis ou progridem de maneira lenta durante $\operatorname{anos}^{30}$. Com o passar do tempo (que irá variar a depender de cada caso analisado), e com a evolução da doença, os déficits se tornam mais graves e há um maior comprometimento para realização das tarefas da vida diária. É frequentemente observada nessa fase a presença dos distúrbios da marcha, tremor e perda da habilidade motora fina, geralmente acompanhando por sintomas psiquiátricos.

No estágio mais avançado da doença o paciente se torna incapaz de realizar atividades simples que anteriormente eram desempenhadas de forma independente e apresenta significativa dificuldade motora ${ }^{29,30}$. No Brasil, as sequelas associadas às doenças oportunistas do SNC, como neurotoxoplasmose, meningite tuberculosa e neurocriptococose, também são consideradas relevantes causas de danos cognitivos e psiquiátricos. Portanto, o diagnóstico correto e precoce destas condições e uma intervenção terapêutica efetiva podem minimizar as complicações neuropsiquiátricas ${ }^{32}$.

Em relação ao dano neurocognitivo que o HIV-1 pode causar, a faixa etária do paciente é fundamental, devido as diferenças significativas da conformação anatômica e funcional do SNC de crianças e adultos. Importante lembrar que a infecção pelo HIV-1 em adultos atinge um cérebro completamente formado e maduro ${ }^{33}$. Poucos dias depois da infecção aguda, o HIV-1 se estabelece no cérebro e pode permanecer clinicamente silente durante muitos anos, até causar alterações funcionais reconhecíveis ${ }^{33}$. Em adultos, usualmente, as manifestações neurocognitivas mais graves aparecem nas fases avançadas da infecção, em pacientes sem tratamento ou com tratamento irregular, 
comprometendo predominantemente a região subcortical ${ }^{34}$. Em adultos, as alterações neuropsicológicas mais frequentes são: o déficit de memória, que abarca uma redução na capacidade de concentração, abstração, planejamento; e a diminuição na velocidade de processamento de informação ${ }^{34}$. Além disso, nos adultos em estágios avançados da doença, o controle motor é um dos domínios mais afetados ${ }^{35}$. Segundo McArthur et $\mathrm{al}^{29}$, a demência pelo HIV-1 pode ser a manifestação neurológica inicial da aids em $5 \%$ dos casos.

Em relação ao dano neurocognitivo causado pelo HIV-1, as crianças são mais vulneráveis e propensas, por terem um cérebro ainda em desenvolvimento ${ }^{36}$. Desde um ponto de vista geral, as manifestações clínicas e o prognóstico da infecção pelo HIV-1 em crianças são classificadas considerando os parâmetros clínicos e imunológicos em diferentes etapas segundo as características clinicas apresentadas ${ }^{37}$. A etapa A é caracterizada por ser uma infecção assintomática, aguda e com uma linfodenopatia generalizada e persistente. A etapa B se caracteriza por ser crônica, sintomática, mas sem as condições definidoras de aids. A etapa $\mathrm{C}$ se caracteriza pela manifestações clínicas indicadoras de aids, entre as quais está a encefalopatia por HIV, sendo que é nesta etapa que se observam as manifestações a nível neuropsicológico.

Em crianças e adolescentes infectados pelo HIV-1, dois tipos de encefalopatias podem ser observadas: (1) uma encefalopatia progressiva caracterizada por microencefalopatia, perdas de habilidades adquiridas anteriormente e anormalidades do trato corticoespinal, e (2) uma encefalopatia estática caracterizada por atrasos cognitivos (principalmente em linguagem, memória, aprendizado e atenção) e motores, mas sem perdas das habilidades adquiridas e sem déficits neurológicos ${ }^{38,39}$.

Alguns estudos ressaltam a importância do estudo das alterações neurológicas e neurocognitivas em crianças infectadas ou expostas ao HIV-1. Bruck et al., em um estudo prospectivo com 83 crianças expostas ao HIV-1, observaram alteração neurológica moderada em $55 \%$ das crianças infectadas ${ }^{40}$. No grupo de crianças expostas ao vírus e não infectadas (ou soro-revertidas) esse comprometimento chegou a 40\%. Tellechea-Rotta e Legido avaliaram uma corte de 340 crianças infectadas pelo HIV-1 por transmissão vertical e encontraram $57 \%$ de sintomas neurológicos ${ }^{41}$ (Tardieu et al $^{42}$., estudaram um 
grupo de 33 crianças em idade escolar com transmissão vertical do HIV-1, e identificaram que 67\% apresentaram habilidades acadêmicas e limitações dentro do normal em testes que avaliaram a inteligência geral, linguagem e função motora ${ }^{42}$. Cognitive assessment of school-age children infected with maternally transmitted human immunodeficiency virus type $1 .{ }^{42}$. Papola et al., estudando 90 crianças em idade escolar, com transmissão vertical do HIV-1, relataram que $56 \%$ estava no limite ou abaixo dos valores esperados nos testes de inteligência ${ }^{43}$. Os domínios cognitivos mais prejudicados em crianças infectadas pelo HIV-1 são: inteligência, funções executivas, memória de trabalho, memória episódica, linguagem, velocidade de processamento, atenção e habilidades motoras ${ }^{44}$.

Crianças infectadas pelo HIV-1 apresentavam comumente altas taxas de encefalopatia grave e progressiva no início da epidemia, variando entre $50 \%$ e $90 \%$. Posteriormente, com a disponibilidade de esquemas antirretrovirais mais eficazes e seguros, a presença de alterações neurocognitivas graves se tornou infrequente em pacientes em uso regular do HAART, situação que, lamentavelmente, é complexa em crianças e adolescente ${ }^{42}$.

\subsection{Tratamento Antirretroviral e HAND}

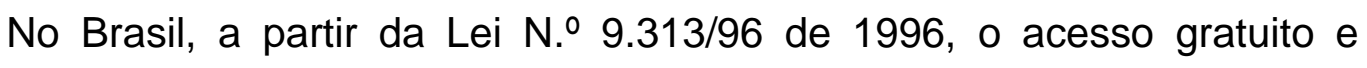
universal ao tratamento antirretroviral foi garantido, melhorando o prognóstico das pessoas quem vivem com HIV/aids (PVHIV). Devido a esse fato histórico, nas décadas seguintes, a doença que era considerada como devastadora e que inevitavelmente levaria à morte, passou a ser entendida como doença potencialmente crônica, desde que o tratamento seja correto ${ }^{14}$. Os objetivos da terapia antirretroviral são dois: do ponto de vista individual, reduzir a mortalidade e morbidade associada ao HIV, melhorando ou mantendo a qualidade de vida dos pacientes e do ponto de vista de saúde pública, diminuir a transmissão do HIV-1. Para atingir ambos objetivos, é importante controlar a replicação do HIV-1, o que permitirá melhorar o número de células CD4, se traduzindo na recuperação ou manutenção do sistema imunológico ${ }^{16}$. Como 
resultado da diminuição da carga viral do HIV-1 e do aumento das células de defesa (linfócitos T-CD4), se observou redução do aparecimento doenças oportunistas, das taxas de hospitalização e dos óbitos decorrentes da aids ${ }^{14}$

Os benefícios do tratamento antirretroviral são evidentes. Contudo, subgrupos de PVHIV, apresentam problemas de adesão, devido aos efeitos tóxicos dos medicamentos, posologia, uso de drogas ilícitas, depressão, entre outros. A dificuldade de adesão ao tratamento antirretroviral pode estar associada, particularmente, à presença de sintomas psiquiátricos, neurocognitivos e/ou comportamentais, identificados no contexto da infecção pelo HIV-1. Por tanto, é importante que o profissional da saúde entenda a complexidade das causas potencias de má adesão, as quais, podem, inclusive, se apresentar de forma concomitante e sinérgica ${ }^{45}$.

Problemas de adesão ao tratamento podem propiciar o surgimento de cepas virais resistentes aos medicamentos, sistemicamente. Contudo, o HIV-1 pode evoluir de forma compartimentalizada e diferenciada, em relação ao vírus circulante em sangue periférico, podendo também interferir na atividade dos medicamentos antirretrovirais ${ }^{46}$.

O controle maior e efetivo da replicação viral, e a melhora do estado imunológico dos pacientes foi possível a partir da introdução de esquemas mais eficientes, seguros e de fácil posologia. Essas características permitiram maiores índices de controle virológico sistêmico, mas não evita, necessariamente, o comprometimento neurocognitivo ${ }^{47,18,48,49}$. Nos últimos anos, têm sido observada uma diminuição importante da incidência de doenças neurológicas, tanto as secundárias (doenças oportunistas), quanto as primárias (demência ligada ao HIV). Contudo, apesar de ter sido observada diminuição da frequência da demência associada ao HIV (HAD) $)^{50,51,52}$, as formas leves e assintomáticas, tem aumentado de forma expressiva.

Em crianças e adolescentes que vivem infectados pelo HIV-1, muitos fatores associados com a doença ameaçam seu bem-estar, podendo citar alguns deles: lidar com a dor de sua doença física; preocupar-se com a saúde física ou prognóstico; frequentes interrupções de atividades sociais e acadêmicas, devido às internações, o estigma e o isolamento social; os medos relacionados à divulgação do diagnóstico; perdas e as preocupações com a própria imagem 
corporal relacionada com a lipodistrofia ou condições dermatológicas associadas com a doença ${ }^{53}$. Para as crianças mais jovens, sentimentos de culpa por ter feito algo de errado para "merecer" à infecção pelo HIV-1 são comuns. Sentimentos de depressão, isolamento social, solidão, raiva e confusão não são incomuns entre os jovens que lutam para lidar com a infecção pelo HIV-1 e a aids. Crianças e adolescentes apresentam altos índices de prevalência de transtornos psiquiátricos: transtorno de déficit de atenção, 29\%; transtornos de ansiedade, $24 \%$; depressão, $25 \%{ }^{54}$. Além disso, crianças infectadas pelo HIV-1, mesmo com estado clínico estável, apresentam problemas importantes de comportamento quando comparados à crianças não infectadas pelo $\mathrm{HIV}-1^{55}$. 


\section{Justificativa do Estudo}

$\mathrm{Na}$ literatura médica existe ampla informação sobre crianças e adolescentes infectados pelo HIV-1, via transmissão vertical. Este estudo foi proposto levando em consideração que existe escassa informação epidemiológica sobre alterações neurocognitivas em adultos HIV-1, infectados via transmissão vertical. Esse tema, inclusive não é abordado no Protocolo Clínico e Diretrizes Terapêuticas (PCDT) para Manejo da Infeção pelo HIV em Crianças e Adolescentes de 2018 assim como no PCDT para Manejo da Infecção pelo HIV em Adultos, também de 2018 . Por esses motivos, foi decidido estudar o tema, inicialmente, para conhecer a dimensão do problema no Serviço de Extensão ao Atendimento de Pacientes HIV/aids, (SEAP), da Divisão de Moléstias Infecciosas e Parasitárias do Hospital das Clínicas, Faculdade de Medicina da Universidade de São Paulo e avaliar ferramentas que possam ser utilizadas em populações semelhantes. 


\section{Objetivos}

\subsection{Objetivo principal}

Determinar a frequência das alterações neurocognitivas associadas ao HIV-1, em adultos infectados por transmissão vertical, em seguimento ambulatorial.

\subsection{Objetivos secundários:}

a. Identificar as principais características demográficas, clínicas e laboratoriais de adultos com HAND, infectados por transmissão vertical;

b. Verificar a frequência de ansiedade e depressão em adultos infectados pelo HIV-1 por transmissão vertical. 


\section{Métodos}

\subsection{Tipo de estudo, período e local}

Trata-se de estudo de delineamento transversal, realizado entre janeiro de 2016 e maio de 2017, no Serviço de Extensão ao Atendimento de Pacientes HIV/aids, (SEAP), da Divisão de Moléstias Infecciosas e Parasitárias do Hospital das Clínicas, Faculdade de Medicina da Universidade de São Paulo. Trata-se de um serviço exclusivamente ambulatorial, localizado na cidade de São Paulo.

\subsection{Critérios de inclusão e exclusão}

Os critérios de inclusão foram: (i) pacientes com diagnóstico de infecção pelo HIV-1 por transmissão vertical; (ii) idade igual ou superior a 18 anos; (iii) escolaridade mínima de 4 anos; e (iv) consentimento para participar do estudo.

Os critérios de exclusão foram: (i) diagnóstico concomitante de doenças neurológicas oportunistas (por exemplo, toxoplasmose cerebral, neurotuberculose, meningite criptocócica, leucoenfalopatia multifocal progressiva); (ii) condições previamente documentadas (traumáticas, metabólicas, vasculares ou degenerativas) que dificultariam a avaliação dos sintomas e sinais neurológicos; (iv) uso de substâncias psicoativas; (v) incapacidade física para aplicação dos testes; e (vi) recusa da assinatura no Termo de Consentimento Livre e Esclarecido. 


\subsection{Procedimentos}

Após aprovação do Projeto pela Comissão de avaliação de projetos de pesquisa (CAPPesq) da Faculdade de Medicina da Universidade de São Paulo (FMUSP), foi solicitada a enfermeira responsável, a Camila Picone, do Setor de pesquisa do SEAP Serviço de Extensão ao Atendimento de Pacientes HIV/aids Casa da aids da Divisão de Moléstias Infecciosas e Parasitárias do Hospital das Clínicas, uma lista com os nomes e telefones dos pacientes em atendimento ambulatorial, infectados por transmissão vertical. A partir disso foi realizado contato telefônico explicando os objetivos do estudo e convidando os pacientes a participar. Caso o paciente aceitasse era combinado dia e horário. A avaliação ocorreu em um único dia para cada paciente. A avaliação teve duração de 1 hora e 30 minutos.

\subsection{Instrumentos}

O questionário estruturado foi utilizado nas entrevistas realizadas para que as informações clínicas e demográficas fossem obtidas (Anexo A). Adicionalmente, foi realizada revisão dos prontuários para uma coleta de dados adicionais, incluindo informações dos exames laboratoriais.

Os dados demográficos e epidemiológicos foram obtidos por meio de um questionário que incluiu: sexo, idade; estado civil, dados clínicos; uso atual e histórico de antirretrovirais; dados laboratoriais; contagem de linfócitos CD4+, quantificação da carga viral do HIV-1. Foram considerados os resultados laboratoriais mais próximos à avaliação clínica (até 3 meses antes).

Para descartar possíveis alterações neurocognitivas secundárias ao uso de substância psicoativas foi utilizado o instrumento denominado teste de triagem do envolvimento com álcool, tabaco e outras substâncias (ASSIST, pelas siglas em inglês: Alcohol, Smoking and Substance Involvement Screening Test) (Anexo B). O teste, desenvolvido em 2002, caracteriza-se por ser autoaplicável e consiste de 8 questões sobre o uso de nove classes de substâncias psicoativas (tabagismo, álcool, maconha, cocaína, estimulantes, sedativos, 
inalantes, alucinógenos e opiáceos). As questões abordam a frequência de uso, na vida e nos últimos 3 meses, problemas relacionados ao uso, preocupação a respeito do uso por parte de pessoas próximas ao usuário, prejuízo na execução de tarefas esperadas, tentativas mal sucedidas de cessar ou reduzir o uso, sentimento de compulsão e uso por via injetável. Cada resposta corresponde a um escore, que varia de 0 a 4 , sendo que a soma total pode variar de 0 a 20. Considera-se a faixa de escore de 0 a 3 , como indicativa de uso ocasional, de 4 a 15 , como indicativa de abuso e $\geq 16$, como sugestiva de dependência. Utilizaremos a versão em português do ASSIST ${ }^{56}$.

A "Escala de Depressão e Ansiedade Hospitalar" (HADS) foi utilizada para avaliação do estado de humor (Anexo C). A HADS é uma medida de autoavaliação de depressão e ansiedade amplamente utilizada em pacientes com doenças físicas, tanto no contexto hospitalar, como em pesquisa. Esta escala contém 14 questões do tipo múltipla escolha, sendo dividida em duas subescalas, para ansiedade e depressão, com sete itens cada. A pontuação global em cada subescala vai de 0 a 21, o corte para depressão é a somatória $\geq 10$ pontos e para ansiedade $\geq 9$ pontos. Dentre suas características destacam-se: os conceitos de depressão e ansiedade ficam separados; não contempla os sintomas vegetativos; a compreensão de depressão é tida pelo conceito de anedonia; tem como destino detectar graus leves de transtornos afetivos em ambientes não psiquiátricos e a responder, o paciente deve levar em consideração como se sentiu durante a última semana ${ }^{57}$.

Para avaliação da queixa cognitiva subjetiva foi utilizado o Questionário Neurocognitivo Breve (Anexo D). Ele é composto por três questões referentes à percepção de dificuldade de memória, atenção e resolução de problemas. Tendo como possibilidade de respostas sim, as vezes e não. O Ministério da Saúde do Brasil recomenda que este questionário seja aplicado no momento do diagnóstico da infecção pelo HIV, antes do início da HAART; depois, anualmente e em pacientes com fatores de risco para HAND, a triagem pode ser realizada a intervalos de 6 meses (Departamento de vigilância, prevenção e controle das IST, do HIV/Aids e das Hepatites Virais) ${ }^{58}$ : 
- Memória ("você tem perda de memória frequente? Esquece-se de eventos especiais ou reuniões, inclusive aquelas mais recentes? ");

- Lentificação psicomotora ("você sente que está mais lento quando pensa, planeja atividades ou resolve problemas? "); e/ou

- Atenção ("você tem dificuldades para prestar atenção, por ex., ao conversar, ler um jornal ou assistir a um filme? ").

Para avaliação das atividades de vida diária foi utilizada a Escala de Lawton $^{59}$, adaptada para o contexto brasileiro em 2008 por Santos e Virtuoso Júnior $^{60}$ (Anexo E). Este questionário é um instrumento de rápida e fácil aplicação, que avalia a capacidade de telefonar, viajar, fazer compras, preparar refeições, fazer trabalhos manuais domésticos, lavar e passar roupas, tomar remédios e cuidar das finanças, sendo seu resultado expresso através de três possibilidades: independência, dependência parcial (necessidade de algum auxílio na execução das tarefas) e dependência completa. Estudos indicam, no entanto, que fatores 15 sociodemográficos, como idade, sexo, arranjo familiar e educação podem exercer influência sobre a capacidade funcional. A pontuação vai de 0 a 21 pontos, sendo: 0-7 pontos: dependência total, 8-20 pontos: dependência parcial e 21 pontos: independência. O resultado desta escala possibilitará a avaliação da condição de realização das tarefas diárias e auxiliar na classificação dos tipos de transtornos neurocognitivos leve ou maior, segundo DSM 5.

Foi aplicado o International HIV Dementia Scale (IHDS), uma ferramenta utilizada para triagem (Anexo F). Essa escala avaliou agilidade motora, velocidade psicomotora e memória em pacientes infectados pelo HIV-1. A pontuação total da IHDS consiste na somatória das pontuações dos três domínios avaliados. A máxima pontuação possível é de 12. O diagnóstico de demência deve ser considerado em paciente com uma pontuação $\leq 10$. (Departamento de vigilância, prevenção e controle das IST, do HIV/Aids e das Hepatites Virais ${ }^{61.62}$.

A avaliação neuropsicológica estruturada tem um papel fundamental na identificação e diagnóstico de transtornos neurocognitivos associados ao HIV. Os testes utilizados nesse estudo foram todos recomendados pela literatura ${ }^{2}$. Funções cognitivas avaliadas e testes utilizados: 


\section{Habilidades Motoras:}

O Grooved Pegboard tem como objetivo avaliar a coordenação e velocidade viso-motora, portanto, este teste requer integração sensório-motor e um alto nível de processamento motor. O mesmo é constituído por uma placa de metal com uma matriz de 25 buracos posicionados aleatoriamente e bastonetes de ferro com ranhuras. Cada bastonete deve ser rodado para coincidir com o buraco, antes de poderem ser inseridos. É solicitado ao examinando que coloque os bastonetes nos buracos, primeiro com a mão dominante e posteriormente com a mão dominante o mais rápido possível ${ }^{63}$.

\section{Funcões Intelectuais:}

A escala Wechsler de inteligência é um instrumento psicométrico com primeira versão desenvolvida por David Wechsler nos Estados Unidos em 1939. Desde então sofreu várias adaptações dando origem a versões mais recentes adaptadas para a população brasileira ${ }^{64}$. O subteste Vocabulário avalia a compreensão, linguagem expressiva e memória semântica, consiste em 33 palavras apresentada em ordem crescente de dificuldade. Cada palavra vem precedida da pergunta "O que é....?", o sujeito deve defini-las da forma que desejar e cada resposta recebe escore de 0 a 2, sendo 0 para respostas incorretas, 1 para resposta especificas e 2 para conceitos gerais.

O Subteste do WAIS-III Raciocínio Matricial da Escala Wechsler de Inteligência para Adultos avalia uma das facetas do funcionamento executivo raciocínio não verbal, através de quatro tarefas: completar padrões, classificação, analogia e raciocínio serial. Consiste em pranchas com séries de padrões incompletas, no qual o examinando deve identificar a parte faltante entre seis alternativas, sendo apenas uma correta. A pontuação varia de 0 para resposta incorreta e ou 1 para resposta correta, totalizando o maior escore bruto possível de $26^{64}$.

\section{Atencão e Função Executiva:}

O Trail Making Test (Partes A e B) acessa a capacidade de manutenção do engajamento mental, o rastreamento visual, a destreza motora e a memória operacional $^{41}$ (Anexo G). O teste consiste em ligar letras na ordem em que 
aparecem no alfabeto (trilhas $\mathrm{A}$ ); ou letras a números, seguindo também a sequência em que aparecem no alfabeto, por exemplo, 1-A-2-B e assim por diante (trilhas B).

A prova de fluência verbal fornece informações acerca da capacidade de armazenamento do sistema de memória semântica, da habilidade de recuperar a informação guardada na memória e do processamento das funções executivas, especialmente, aquelas através da capacidade de organizar o pensamento e as estratégias utilizadas para a busca de palavras. O teste de fluência verbal envolve a geração do maior número de palavras possíveis em período de tempo fixado. Existe o teste de fluência fonológica com a evocação de palavras que começam com uma certa letra, normalmente F, A ou S e a fluência por categoria ou semântica com a geração de palavras de certa classe semântica como, por exemplo, categoria "animal"65.

Fluência Verbal Semântica ou Categórica: Animais - Solicita-se que 0 indivíduo fale o maior número de animais que conseguir em 1 minuto. (Strauss $\mathrm{E}$, Sherman E, Spreen O. A compendium of neuropsychological tests: Administration, norms, and commentary. 3 ed. New York: Oxford University Press; 2006.)

\section{Velocidade de Processamento das Informacões:}

No subteste Códigos da escala WAIS-III13 o examinando deve copiar símbolos simples que estão associados com números. Usando uma chave, o examinando desenha símbolos sob o número correspondente. A pontuação é determinada pelo número de símbolos escritos corretamente, dentro do tempo limite de 120 segundos. O objetivo é medir a velocidade de informação (tempo requerido para processar as informações), memória de curto prazo, aprendizado, percepção visual, coordenação motora e visual, amplitude visual, atenção e motivação. Avalia o tempo que o cérebro requer para processar uma informação.

\section{Memória: Curto Prazo ou Operacional}

No subteste Dígitos ordem direta ou spam de dígitos da escala WAIS-III: Avalia o subsistema fonológico da memória operacional (na ordem direta). Sequencias crescentes de dígitos são apresentadas oralmente na velocidade 
de um por segundo. Ao fim de cada sequencia os sujeitos devem repeti-la na ordem direta. O teste termina quando ocorrem erros em duas sequencias de mesmo número de dígitos. O escore é o número de dígitos contidos na sequencia máxima repetida corretamente ${ }^{66}$.

No subteste Dígitos de ordem inversa da escala WAIS-III: Sequencias de dígitos são apresentadas oralmente na velocidade de um por segundo. Ao final de cada sequencia os sujeitos devem repeti-la na ordem inversa. $O$ teste termina quando ocorrem erros em duas sequencias de mesmo número de dígitos. O escore é o número de dígitos contidos na sequencia máxima repetida corretamente ${ }^{66}$.

\section{Memória: Auditiva Imediata e Tardia: Visual Imediata e Tardia:}

A Figura Complexa de Rey é uma medida bastante conhecida de construção visuo-espacial e memória não-verba| ${ }^{32}$.

Para a correção dos testes neuropsicológicos, foi calculado o escore bruto (pontuação total feita pelo paciente em cada teste) para obtenção do percentil e 19 classificação do desempenho. Nos subtestes da escala WAIS III após o escore bruto, a tabela do manual fornece o ponto ponderado que é transformado em percentil e classificação. Nos demais testes são calculados os Zs escores, que é a pontuação do paciente menos a média da população normativa dividida pelo desvio padrão. Após a obtenção do $Z$ escore é encontrado percentil e a classificação. Cada teste tem sua tabela normativa que pode ser dividida em idade e ou escolaridade 


\section{Análise Estatística}

Para o cálculo da amostragem, usamos uma técnica não probabilística (amostragem intencional por conveniência), na qual foram incluídos os pacientes que aceitaram participar da pesquisa no período proposto e que preencheram nossos critérios de inclusão.

Os dados coletados foram inseridos em um banco de dados e tratados por meio de estatística descritiva, com cálculos de percentuais, medianas e variação, média e desvio padrão, quando apropriado.

Para a comparação do desempenho neuropsicológico entre grupos, foram realizadas análises de variância para amostras independentes com 1 fator (one-way ANOVA), dessa forma puderam ser identificadas possíveis covariáveis associadas ao desempenho neuropsicológico dos participantes (sexo, idade, escolaridade e depressão). Foi realizado teste qui-quadrado para verificar se existia diferença significativa em dados que utilizaram frequência. Para identificar em quais pares de grupos encontramos diferenças estatísticas foi utilizado o teste Post-Hoc de Bonferoni. Todas as análises quantitativas foram realizadas com o programa estatístico SPSS (21.0) e $p<0,05$ foi estabelecido como nível de significância. ${ }^{67}$ 


\section{Aspectos Éticos}

O estudo foi realizado somente com os participantes que assinaram 0 Termo de Consentimento Livre e Esclarecido (TCLE) (Anexo H). Nesse documento constava os objetivos do estudo e os instrumentos que foram utilizados na pesquisa em uma linguagem de fácil compreensão. Os participantes tiveram liberdade durante todo o estudo de desistir de participar da pesquisa a qualquer momento, e foram informados que essa decisão não iria interferir na continuidade de seu tratamento na Instituição. O sigilo foi mantido em tempo integral. 


\section{Resultados}

\subsection{Seleção dos participantes}

Inicialmente, foram identificados 80 potenciais participantes. Desses, 52 foram excluídos, e a Figura 1 especifica os motivos. Dessa forma, 28 pacientes foram incluídos na pesquisa.

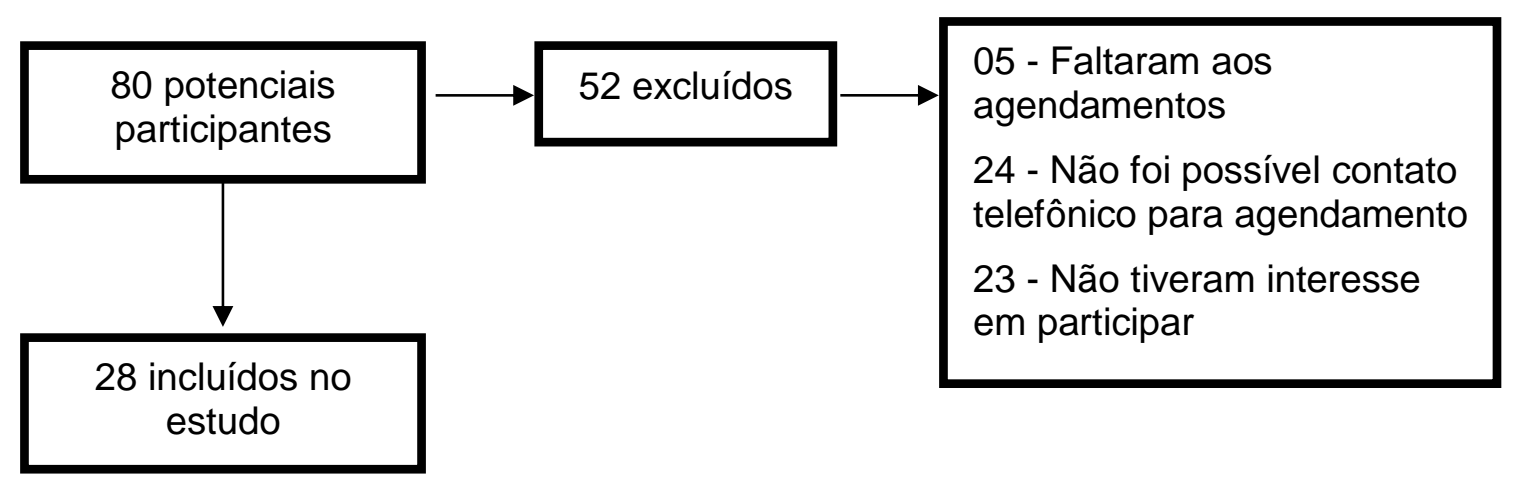

Figura 1. Fluxograma dos pacientes entrevistados e incluídos na amostra

\subsection{Dados demográficos e gerais do população estudada}

Participantes do sexo feminino compuseram a maior parte da amostra ( $n=15,53.6 \%$ ). A idade média dos participantes foi de 22 anos (DP $=6.7$ ). Em sua maioria solteiros $(n=26,92.8 \%)$. A média dos anos de educação foi de 11.3 $(\mathrm{DP}=2.3)$. 
Tabela 1. Distribuição dos pacientes adultos infectados pelo HIV-1 via transmissão vertical sem alteração neurocognitiva, ANI, MND, e HAD, segundo características sociodemográficas

\begin{tabular}{|c|c|c|c|c|c|c|c|c|}
\hline Variáveis & Categoria & $\begin{array}{l}\text { Total } \\
(n=28)\end{array}$ & $\begin{array}{c}\text { Normal } \\
(n=5)\end{array}$ & $\begin{array}{c}\text { ANI } \\
(n=12)\end{array}$ & $\begin{array}{l}\text { MND } \\
(n=6)\end{array}$ & $\begin{array}{l}\text { HAD } \\
(n=5)\end{array}$ & $\begin{array}{l}\text { SIGN. } \\
\text { P }\end{array}$ & $\begin{array}{l}\text { Post } \\
\text { Hoc }\end{array}$ \\
\hline \multirow[t]{3}{*}{ Sexo } & & & & & & & 0.36 & \\
\hline & Masculino & $13(46.4 \%)$ & $4(80 \%)$ & $4(33.3 \%)$ & $3(50 \%)$ & $2(40 \%)$ & & \\
\hline & Feminino & 15 (53.6\%) & $1(20 \%)$ & $8(66.6 \%)$ & $3(50 \%)$ & $3(60 \%)$ & & \\
\hline $\begin{array}{l}\text { Idade (anos) } \\
\text { média } \pm D P\end{array}$ & & $22(6.7)$ & $27.2(5.6)$ & $20.16(0.6)$ & $21.50(1.0)$ & $24.00(4.1)$ & 0.24 & \\
\hline $\begin{array}{l}\text { Escolaridade } \\
\text { (anos) } \\
\text { média } \pm D P\end{array}$ & & $11.3(2.3)$ & $12.40(2.3)$ & $10.91(1.4)$ & $9.66(2.3)$ & $13.00(2.8)$ & 0.05 & \\
\hline \multirow[t]{3}{*}{ Estado Civil } & & & & & & & 0.65 & \\
\hline & Solteiro & $26(92.8 \%)$ & $5(100 \%)$ & $11(91.7 \%)$ & $5(83.3 \%)$ & $5(100 \%)$ & & \\
\hline & Casado & $2(7.2 \%)$ & $0(0 \%)$ & $1(8.3 \%)$ & $1(16.7 \%)$ & $0(0 \%)$ & & \\
\hline \multirow[t]{4}{*}{ Ocupação } & & & & & & & 0.03 & a \\
\hline & Estudante & $14(50 \%)$ & $1(20 \%)$ & $9(75 \%)$ & 2 (33.3\%) & $2(40 \%)$ & & \\
\hline & Do lar & $3(10.7 \%)$ & $0(0 \%)$ & $1(8.3 \%)$ & $0(0 \%)$ & $2(40 \%)$ & & \\
\hline & $\begin{array}{l}\text { Serviços } \\
\text { gerais }\end{array}$ & 11 (39.3\%) & $4(80 \%)$ & $2(16.7)$ & $4(66.7 \%)$ & $1(20 \%)$ & & \\
\hline
\end{tabular}

A: Sem alteração x ANI; B: Sem alteração x MND; C: Sem alteração x HAD; D: ANI x MDN; E: ANI x HAD; F: MND x HAD. ANI (asymptomatic neurocognitive impairment); MND (mild neurocognitive disorder); HAD (HIV-associated dementia)

\subsection{Frequência de HAND em adultos infectados pelo HIV-1 via transmissão vertical}

Tendo como base os critérios de classificação de HAND, foram encontrados 5 participantes (17.9\%) com desempenho neurocognitivo normal e $23(82.1 \%)$ participantes com alguma categoria de HAND. Dentre eles, 12 participantes (42.9\%) tiveram ANI, 6 participantes (21.4\%) tiveram MND e 5 participantes (17.9\%) apresentaram HAD. O Gráfico 1 apresenta o número de participantes de acordo com a classificação HAND. 
Gráfico 1. Frequência das alterações neurocognitivas associadas ao HIV-1 em adultos infectados pelo HIV-1 via transmissão vertical.

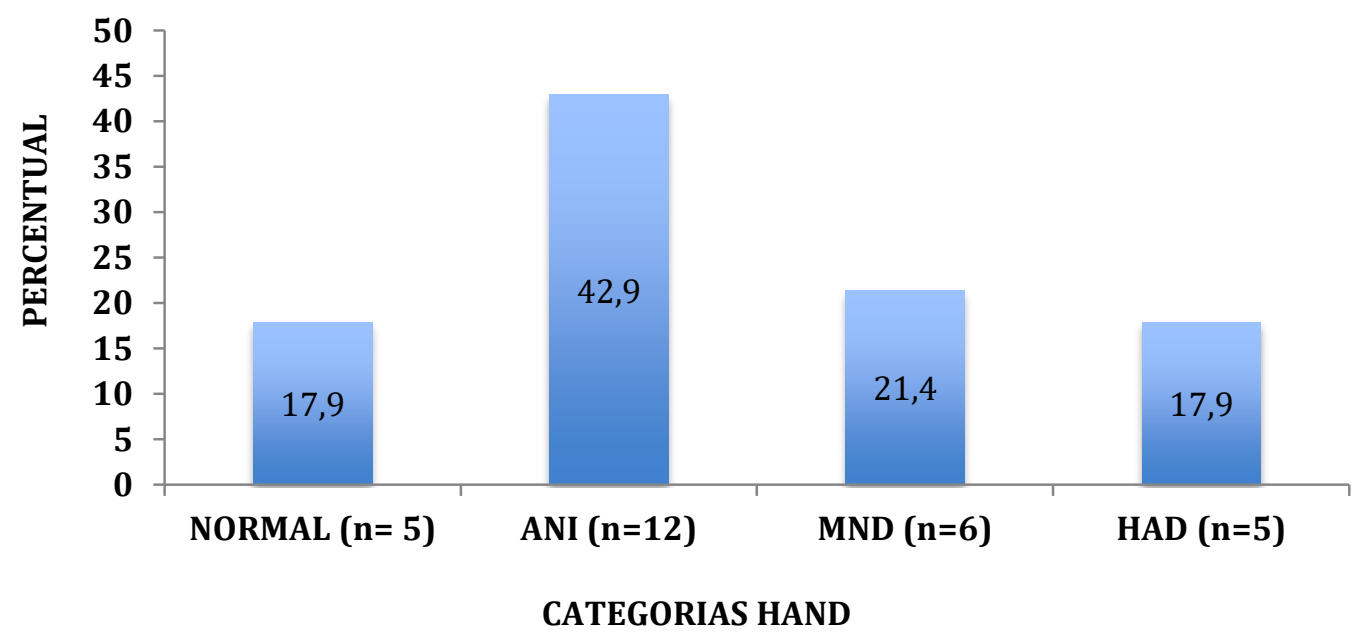

\subsection{Dados laboratoriais}

De acordo com a análise realizada nesse estudo, a média da contagem dos linfócitos T-CD4 dos participantes foi 500 células $/ \mathrm{mm}^{3}$ (DP: 261,9), sendo que a maioria $(n=16,57.1 \%)$ apresentou carga viral detectável. Não foi encontrada significância estatística na análise clínica laboratorial na associação entre as variáveis em função da classificação de HAND, como mostra a Tabela 2. 
Tabela 2: Distribuição dos dados laboratoriais de pacientes adultos infectados pelo HIV-1 via transmissão vertical, de acordo com as categorias HAND

\begin{tabular}{|c|c|c|c|c|c|c|c|}
\hline Variáveis & Categoria & $\begin{array}{l}\text { Total } \\
(n=28)\end{array}$ & $\begin{array}{c}\text { Normal } \\
(n=5)\end{array}$ & $\begin{array}{c}\text { ANI } \\
(n=12)\end{array}$ & $\begin{array}{l}\text { MND } \\
(n=6)\end{array}$ & $\begin{array}{l}\text { HAD } \\
(n=5)\end{array}$ & $\begin{array}{c}\text { Signt. } \\
\mathbf{p}\end{array}$ \\
\hline $\begin{array}{l}\text { CD4+, } \\
\text { células } / \mathrm{mm}^{3} \\
\text { média } \pm \mathrm{DP}\end{array}$ & $500.3(298.3)$ & & $587(90.3)$ & 601 (377.4) & 335 (207.0) & 356 (248.3) & 0.32 \\
\hline Carga Viral ${ }^{*}$ & & & & & & & 0.21 \\
\hline & Indetectável & 12 (42.9\%) & $4(80 \%)$ & $3(25 \%)$ & $3(50 \%)$ & $2(40 \%)$ & \\
\hline & Detectável & $16(57.1 \%)$ & $1(20 \%)$ & $9(75 \%)$ & $3(50 \%)$ & $3(60 \%)$ & \\
\hline $\begin{array}{l}\text { Glicose, } \\
\text { MG/dL } \\
\text { média } \pm D P\end{array}$ & & $77.2(10.0)$ & $81.2(6.3)$ & $80.80(3.2)$ & $72.66(2.2)$ & $70.25(0.3)$ & 0.39 \\
\hline $\begin{array}{l}\text { Hemoglobina } \\
\text { MG/dL } \\
\text { média } \pm \text { DP }\end{array}$ & & $13.9(1.6)$ & $14.6(0.4)$ & $14.1(0.5)$ & $13.7(0.9)$ & $13.2(0.5)$ & 0.43 \\
\hline $\begin{array}{l}\text { Colesterol } \\
\text { total } \\
\text { MG/dL } \\
\text { média } \pm D P\end{array}$ & & $151.8(45.3)$ & $136.4(34.6)$ & $152.9(12.1)$ & $149.6(16.8)$ & $167.8(15.6)$ & 0.52 \\
\hline 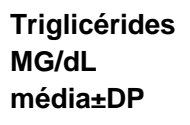 & & $111.6(58.5)$ & $135.6(32.2)$ & $111.0(16.1)$ & $122.2(35.1)$ & $69.5(11.5)$ & 0.35 \\
\hline $\begin{array}{l}\text { Colesterol } \\
\text { LDL } \\
\text { MG/dL } \\
\text { média } \pm D P\end{array}$ & & $94.7(28.9)$ & $92.6(14.0)$ & $94.0(9,0)$ & $84.2(11.5)$ & $108.6(16.9)$ & 0.25 \\
\hline $\begin{array}{l}\text { Colesterol } \\
\mathrm{HDL} \\
\mathrm{MG} / \mathrm{dL} \\
\text { média } \pm \mathrm{DP}\end{array}$ & & $39.7(9.7)$ & $37.8(3.7)$ & $37.3(3.7)$ & $40.8(5.7)$ & $44.4(3.2)$ & 0.52 \\
\hline $\begin{array}{l}\text { Colesterol } \\
\text { VLDL } \\
\text { MG/dL } \\
\text { média } \pm D P\end{array}$ & & $23.5(12.1)$ & $27.2(6.5)$ & $22.1(3.3)$ & $24.6(7.0)$ & $20.8(5.9)$ & 0.59 \\
\hline $\begin{array}{l}\text { CPE } \\
\text { (pontuação) }\end{array}$ & & $7.2(2.3)$ & $7.3(0.8)$ & $6.8(0.9)$ & $8.0(0.9)$ & $7.2(0.8)$ & 0.62 \\
\hline
\end{tabular}




\subsection{Frequência de ansiedade/depressão em adultos infectados pelo HIV-1 via transmissão vertical}

Foi observado que $39,3 \%$ dos pacientes avaliados nesse estudo apresentaram sintomas de ansiedade e em 10,7\% da amostra total foram identificados sintomas de depressão.

$\mathrm{Na}$ Tabela 3 se mostram as frequências de ansiedade e depressão, segundo categoria de HAND. Nenhum participante com ANI ou MND apresentou depressão, em contraste, 60\% dos participantes com HAD, apresentaram depressão $(p=0.01)$.

Tabela 3. Frequência de Depressão e Ansiedade em pacientes adultos portadores de HIV-1 infectados via transmissão vertical de acordo com as classificações de HAND

\begin{tabular}{|c|c|c|c|c|c|c|c|c|}
\hline Variáveis & Categoria & $\begin{array}{l}\text { Total } \\
(n=28)\end{array}$ & $\begin{array}{c}\text { Normal } \\
(n=5)\end{array}$ & $\begin{array}{c}\text { ANI } \\
(n=12)\end{array}$ & $\begin{array}{l}\text { MND } \\
(n=6)\end{array}$ & $\begin{array}{l}\text { HAD } \\
(n=5)\end{array}$ & $\begin{array}{c}\text { Signf } \\
\mathbf{p}\end{array}$ & $\begin{array}{l}\text { Post } \\
\text { Hoc }\end{array}$ \\
\hline \multirow[t]{3}{*}{ Ansiedade } & & & & & & & 0.61 & \\
\hline & Não & 17 (60.7\%) & $4(80 \%)$ & 7 (58.3\%) & $4(66.7 \%)$ & $2(40 \%)$ & & \\
\hline & Sim & $11(39.3 \%)$ & $1(20 \%)$ & $5(41.7 \%)$ & 2 (33.3\%) & $3(60 \%)$ & & \\
\hline \multirow[t]{3}{*}{ Depressão } & & & & & & & $<0.01$ & $c, e$ \\
\hline & Não & 25 (89.3\%) & $5(100 \%)$ & 12 (100\%) & $6(100 \%)$ & $2(40 \%)$ & & \\
\hline & Sim & $3(10.7 \%)$ & 0 & 0 & 0 & $3(60 \%)$ & & \\
\hline
\end{tabular}

A: Sem alteração x ANI; B: Sem alteração x MND; C: Sem alteração x HAD; D: ANI x MDN; E: ANI x HAD; F: MND x HAD. ANI (asymptomatic neurocognitive impairment); MND (mild neurocognitive disorder); HAD (HIV-associated dementia)

\subsection{Avaliação do questionário neuropsicológico breve}

Foi observado que $64,3 \%$ dos pacientes avaliados nesse estudo apresentaram alguma alteração na memória. Vale ressaltar que somente pacientes que tinham HAND apresentaram alterações nessa categoria. Em $39,3 \%$ desse grupo foi identificada alentecimento psicomotor. E 50\% da amostra apresentou alteração na atenção. 
A análise dos resultados de autorrelato do Questionário Neurocognitivo Breve com a classificação de HAND mostrou a significância estatística na percepção subjetiva de alteração na atenção $(p=0.001)$, e lentificação $(p=0.05)$, ou seja, os pacientes com HAD relataram mais queixas de atenção e lentificação que os pacientes dos outros dois grupos. Como pode ser visto na Tabela 4.

Tabela 4. Questionário Neurocognitivo Breve dos pacientes adultos portadores de HIV-1 infectados via transmissão vertical avaliados através das categorias HAND: resultados baseados no autorrelato dos pacientes

\begin{tabular}{|c|c|c|c|c|c|c|c|}
\hline Variáveis & Categoria & $\begin{array}{c}\text { Normal } \\
(n=5)\end{array}$ & $\begin{array}{c}\text { ANI } \\
(n=12)\end{array}$ & $\begin{array}{l}\text { MND } \\
(n=6)\end{array}$ & $\begin{array}{l}\text { HAD } \\
(n=5)\end{array}$ & $\begin{array}{c}\text { Signf. } \\
\text { p }\end{array}$ & $\begin{array}{l}\text { PosT } \\
\text { Hoc }\end{array}$ \\
\hline \multirow[t]{4}{*}{ Memória } & & & & & & 0.56 & \\
\hline & Sim & 0 & $2(16.7 \%)$ & $1(16.7 \%)$ & 2 (40\%) & & \\
\hline & As Vezes & $2(40 \%)$ & $5(45 \%)$ & $4(66.7 \%)$ & $2(40 \%)$ & & \\
\hline & Não & $3(60 \%)$ & $5(45 \%)$ & $1(16.7 \%)$ & $1(20 \%)$ & & \\
\hline \multirow[t]{4}{*}{ Lentificação } & & & & & & 0.05 & e \\
\hline & Sim & 0 & 0 & 0 & $2(40 \%)$ & & \\
\hline & As vezes & $1(20 \%)$ & $3(25 \%)$ & $3(50 \%)$ & $2(40 \%)$ & & \\
\hline & Não & $4(80 \%)$ & $9(75 \%)$ & $3(50 \%)$ & $1(20 \%)$ & & \\
\hline \multirow[t]{4}{*}{ Atenção } & & & & & & $<0.001$ & $\mathrm{~b} ; \mathrm{c} ; \mathrm{d} ; \mathrm{e}$ \\
\hline & Sim & 0 & 0 & $1(16.7 \%)$ & $4(80 \%)$ & & \\
\hline & As vezes & $1(20 \%)$ & $3(25 \%)$ & 5 (66.7\%) & 0 & & \\
\hline & Não & $4(80 \%)$ & $9(75 \%)$ & 0 & $1(20 \%)$ & & \\
\hline
\end{tabular}

* A: Sem alteração x ANI; B: Sem alteração x MND; C: Sem alteração x HAD; D: ANI x MDN; E: ANI x HAD; F: MND x HAD. ANI (asymptomatic neurocognitive impairment); MND (mild neurocognitive disorder); HAD (HIV-associated dementia)

\subsection{Avaliação neuropsicológica por domínios neurocognitivos}

A análise do desempenho de cada teste da bateria neuropsicológica formal mostrou que houve relevância estatística e diferenças significativas entre os grupos nas seguintes esferas neuropsicológicas: atenção, velocidade de processamento e velocidade motora. As diferenças estatisticamente significativas entre os grupos foram identificadas principalmente quando comparado a forma mais grave de HAND (HAD). Os participantes com ANI e MND obtiveram resultados significativamente superiores àqueles com HAD nos seguintes testes e funções: Trail Making A (atenção sustentada), Trail Making B (atenção alternada). Os pacientes sem comprometimento neurocognitivo 
apresentaram melhor desempenho no teste Grooved Pegboard, que avaliou velocidade motora, quando comparados aos pacientes com HAD.

Os participantes classificados com ANI apresentaram desempenho significativamente superior aos pacientes classificados como MND no teste Códigos, que avaliou velocidade de processamento de informações. A Tabela 5 apresenta os resultados obtidos para cada categoria de pacientes, segundo os domínios neurocognitivos.

Tabela 5. Distribuição da performance cognitiva dos pacientes adultos, infectados pelo HIV-1 via transmissão vertical, na bateria neuropsicológica, de acordo com a classificação de HAND

\begin{tabular}{|c|c|c|c|c|c|c|c|}
\hline $\begin{array}{c}\text { Domínios } \\
\text { Neurognitivos }\end{array}$ & Categoria & $\begin{array}{c}\text { Normal } \\
(n=5)\end{array}$ & $\begin{array}{c}\text { ANI } \\
(n=12)\end{array}$ & $\begin{array}{l}\text { MND } \\
(n=6)\end{array}$ & $\begin{array}{l}\text { HAD } \\
(n=5)\end{array}$ & $\begin{array}{l}\text { Sign. } \\
\text { p }\end{array}$ & $\begin{array}{l}\text { Post } \\
\text { Hoc }\end{array}$ \\
\hline \multicolumn{8}{|l|}{ Função Intelectual } \\
\hline & Vocabulário & $33.4(5.6)$ & $25.3(9.0)$ & $27.8(7.6)$ & $129.2(18.8)$ & 0.56 & \\
\hline & $\begin{array}{l}\text { Raciocínio } \\
\text { Matricial }\end{array}$ & $17.0(4.1)$ & $14.5(4.5)$ & $15.2(4.4)$ & $13.0(6.0)$ & 0.59 & \\
\hline & Ql estimado & $97.6(7.9)$ & $81.9(26.0)$ & $94.5(5.6)$ & $73.0(36.0)$ & 0.30 & \\
\hline \multicolumn{8}{|l|}{ Memória } \\
\hline & Dígitos & $11.8(2.6)$ & $19.0(22.5)$ & $12.7(3.7)$ & $13.80(2.2)$ & 0.76 & \\
\hline & $\begin{array}{l}\text { RAVLT- } \\
\text { Imediata }\end{array}$ & $48.8(7.4)$ & $46.1(10.3)$ & $48.5(5.2)$ & $39.80(16.0)$ & 0.48 & \\
\hline & RAVLT - tardia & $10.0(2.2)$ & $9.2(2.9)$ & $10.0(2.6)$ & $6.20(5.3)$ & 0.22 & \\
\hline & $\begin{array}{l}\text { RAVLT- } \\
\text { reconhecimento }\end{array}$ & $10.8(4.8)$ & $12.7(4.3)$ & $13.3(1.4)$ & $7.80(5.9)$ & 0.15 & \\
\hline & $\begin{array}{l}\text { Figura Rey - } \\
\text { imediata }\end{array}$ & $18.6(7.8)$ & $13.2(7.2)$ & $11.3(6.9)$ & $14.5(10.7)$ & 0.47 & \\
\hline & $\begin{array}{c}\text { Figura Rey - } \\
\text { tardia }\end{array}$ & $18.5(7.3)$ & $14.1(6.7)$ & $11.8(7.0)$ & $13.60(10.7)$ & 0.54 & \\
\hline \multicolumn{8}{|l|}{ Visuoconstrução } \\
\hline & $\begin{array}{l}\text { Figura Rey - } \\
\text { cópia }\end{array}$ & $31.0(5.1)$ & $29.7(4.3)$ & $26.6(5.5)$ & $22.10(10.9)$ & 0.10 & \\
\hline \multicolumn{8}{|l|}{ Atenção } \\
\hline & Trail Making A & $33.6(6.4)$ & $29.7(6.6)$ & $31.8(10.0)$ & $50.6(18.2)$ & $<0.01$ & $e, f$ \\
\hline & Trail Making B & $69.2(14.8)$ & $72.0(19.0)$ & $92.5(29.2)$ & $118.0(63.8)$ & 0.05 & $e, f$ \\
\hline \multicolumn{8}{|l|}{$\begin{array}{l}\text { Velocidade de } \\
\text { Processamento }\end{array}$} \\
\hline & Códigos & $59.8(11.1)$ & $63.91(11.4)$ & $37.00(19.2)$ & $48.6(16.2)$ & $<0.01$ & $d$ \\
\hline \multicolumn{8}{|l|}{ Função Executiva } \\
\hline & F.A.S. & $36.6(13.5)$ & $31.4(9.6)$ & $25.0(5.2)$ & $33.8(12.3)$ & 0.29 & \\
\hline & Animais & $18.8(3.6)$ & $16.5(3.1)$ & $16.8(3.8)$ & $17.00(3.3)$ & 0.64 & \\
\hline \multicolumn{8}{|l|}{ Velocidade Motora } \\
\hline & $\begin{array}{l}\text { Grooved Mão } \\
\text { Dominante }\end{array}$ & $64.4(9.7)$ & $66.1(10.4)$ & $69.8(11.5)$ & $97.8(46.0)$ & 0.04 & c \\
\hline & $\begin{array}{l}\text { Grooved Mão } \\
\text { Não Dominante }\end{array}$ & $47.2(27.3)$ & $77.1(17.0)$ & $72.50(6.0)$ & $86.6(27.0)$ & 0.02 & c \\
\hline
\end{tabular}

* RAVLT: Rey Auditory-Verbal Learning Test; A: Sem alteração x ANI; B: Sem alteração x MND; C: Sem alteração x HAD; D: ANI x MDN; E: ANI x HAD; F: MND x HAD. ANI (asymptomatic neurocognitive impairment); MND (mild neurocognitive disorder); HAD (HIV-associated dementia). 
Foi observado que tanto na Escala de Rastreio Cognitivo de HAND (IHDS) quanto na Escala de Atividade de Vida Diária (Lawton) os pacientes com HAD apresentaram uma pontuação mais baixa quando comparados com as demais categorias. Entretanto, foi observada diferença significativa somente na escala de vida diária. Os dados referentes a distribuição da pontuação de acordo com cada categoria se encontram na tabela 6 a seguir.

Tabela 6. Distribuição da performance cognitiva dos pacientes adultos, infectados pelo HIV-1 via transmissão vertical, nas Escalas de Rastreio de HAND e de AVDs, de acordo com a classificação de HAND

\begin{tabular}{lcccccc}
\hline \multicolumn{1}{c}{ Escalas } & $\begin{array}{c}\text { Normal } \\
(\mathbf{n}=5)\end{array}$ & $\begin{array}{c}\text { ANI } \\
(\mathbf{n}=\mathbf{1 2})\end{array}$ & $\begin{array}{c}\text { MND } \\
(\mathbf{n}=6)\end{array}$ & $\begin{array}{c}\text { HAD } \\
(\mathbf{n}=5)\end{array}$ & $\begin{array}{c}\text { Sign. } \\
\mathbf{p}\end{array}$ & Post Hoc \\
\hline $\begin{array}{l}\text { Escala de } \\
\text { Rastreio de } \\
\text { HAND - IHDS }\end{array}$ & $11.1(1.0)$ & $11.5(0.6)$ & $11.3(0.5)$ & $10.8(1.1)$ & 0.39 & \\
\hline $\begin{array}{l}\text { Escala de AVDs } \\
- \text { Lawton }\end{array}$ & $20.8(0.5)$ & $20.9(0.3)$ & $20.3(0.5)$ & $19.0(1.4)$ & $<0.01$ & a,e,f \\
\hline
\end{tabular}

IHDS: International HIV Dementia Scale; AVDs: atividades de vida diária. A: Sem alteração $x$ ANI; B: Sem alteração $x$ MND; C: Sem alteração x HAD; D: ANI x MDN; E: ANI x HAD; F: MND x HAD. ANI (asymptomatic neurocognitive impairment); MND (mild neurocognitive disorder); HAD (HIV-associated dementia). 


\section{Discussão}

Os principais achados deste estudo foram os seguintes: (i) elevada frequência de HAND em adultos infectados pelo HIV-1 via transmissão vertical (82.2\%); (ii) a idade média dos participantes foi 22 anos, as mulheres representaram $53.6 \%$ da amostra e $92.8 \%$ eram solteiros. O tempo médio de educação foi de 11.3 anos. A média da contagem dos linfócitos T-CD4 dos participantes foi 500 células $/ \mathrm{mm}^{3}$ e $57.1 \%$ apresentou carga viral detectável; (iii) baixa frequência de depressão (10.7\%) na população total, mas elevada frequência dentre os pacientes com HAD (60\%).

A frequência de HAND em adultos infectados por transmissão vertical, observada nessa pesquisa, foi superior a qualquer outro estudo realizado com pacientes adultos ${ }^{68}$. Diante a escassa informação de estudos avaliando o perfil dos participantes da nossa pesquisa, tivemos que realizar comparações utilizando dados de adultos infectados pelo HIV-1 via transmissão sexual. Nesta população, a frequência de HAND tem sido relatada ao redor de $50 \%{ }^{69}$. No Brasil, poucos estudos têm sido realizados sobre a frequência de HAND, e não identificamos estudos publicados em adultos infectados pelo HIV-1 via transmissão vertical. Estudos realizados em diferentes regiões brasileiras indicaram frequência de HAND entre 4,6\% e 73,4\%. ${ }^{70,71,72,73}$. Possíveis justificativas para essa variabilidade incluem: os diferentes instrumentos utilizados nas pesquisas; o tamanho da população estudada; os critérios utilizados para definir HAND; e limitações no controle de variáveis capazes de influenciar os resultados dos exames neuropsicológicos (por exemplo, nível de escolaridade, desemprego, depressão e presença de comorbidades) ${ }^{74}$.

Adicionalmente, diferente do identificado no presente trabalho, onde as formas sintomáticas de HAND representaram 39\% dos casos (HAD: $17.9 \%$ e MND: $21.4 \%$ ), essas frequencias em adultos infectados pelo HIV-1 via transmissão sexual tem sido menores. No estudo CHARTER, realizado nos Estados Unidos de América, as frequências de HAD e MND foram 2\% e 12\%, 
respectivamente. No estudo realizado no Instituto de Infectologia Emílio Ribas, em São Paulo, as frequências de HAD e MND foram 6\% e 16\%, respectivamente. A maior frequencia de HAND assim como, principalmente, a maior frequencia de HAD, observadas no presente estudo, tem diversas causalidades. Como a transmissão do vírus pode ocorrer desde os primeiros estágios do desenvolvimento humano e porque o cérebro é um dos primeiros e principais alvos e santuários da infecção pelo $\mathrm{HIV}^{75,76}$, espera-se que o comprometimento cognitivo seja, consequentemente, elevado, principalmente se o paciente não recebeu terapia antirretroviral, adequadamente, ou se não recebeu essa intervenção oportunamente. Isso fica demonstrado com os relatos que indicam que $13-35 \%$ das crianças infectadas pelo HIV-1 via transmissão vertical, não tratadas, desenvolvem encefalopatia progressiva pelo HIV-1, sendo que a maioria dessas crianças manifestam essa condição durante o primeiro ano de vida ${ }^{77}$.

Além da ação do próprio vírus, a própria resposta imunológica do hospedeiro, expressada mediante os fenômenos de inflamação e imunoativação celular, também cumpre papel importante nos mecanismos de dano cerebral ${ }^{78}$. Por tanto, os efeitos neurocognitivos precoces do HIV-1, nas crianças, obedecem a uma combinação de efeitos diretos e indiretos sobre a função cerebral. Contudo, existe uma variabilidade individual, ainda pouco compreendida, de uma somatória de fatores potencialmente contributórios para o aparecimento ou acentuação de alterações neurocognitivas em crianças e adolescentes, como predisposição genética, concomitância de doenças neurológicas oportunistas ou neuropsiquiátricas, desnutrição, uso álcool e de drogas ilícitas, assim como o próprio contexto psicossocial ${ }^{76}$.

Assim como demonstrado em adultos, o uso de terapia antirretroviral tem evidenciado benefícios diretos na mortalidade de morbidade de crianças infectadas pelo HIV-1 via transmissão vertical. O tratamento antirretroviral, se utilizado adequadamente, pode suprimir a replicação sistêmica do HIV-1 e melhorar a imunidade, mas também pode melhorar o estatus nutricional, reduzir as internações hospitalares e melhorar a qualidade de vida familiar ${ }^{79}$.

Em adultos, o impacto da terapia antirretroviral altamente eficaz tem sido importante nas variações das frequências relativas de cada categoria de 
HAND, embora a frequência global de HAND se mantenha similar ao observado antes da disponibilidade dessa terapia ${ }^{68}$. Impacto similar poderia ser esperado nas crianças e adolescentes infectadas pelo HIV-1 via transmissão vertical, mas esse aspecto está menos definido. Na literatura médica se desconhece se a terapia antirretroviral tem reduzido, categoricamente, as formas mais graves das alterações neurocognitivas e aumentado as formas mais leves, nas crianças e adolescentes infectadas pelo HIV-1 via transmissão vertical $^{80}$. Nesse sentido, um estudo mostrou que a frequência de encefalopatia pelo HIV-1, diminui de $40 \%$ para $18 \%$, após a disponibilidade de terapia antirretroviral mais eficaz, sugerindo que o tratamento está associado à melhora dos desfechos neurocognitivos em crianças infectadas pelo HIV-1 via transmissão vertical ${ }^{81}$.

Nosso achado de elevada frequência de HAD sugere que, mesmo em contexto de disponibilidade de terapia antirretroviral universal e gratuita, o impacto do tratamento não foi proporcional ao observado em adultos, mas existem uma série de variáveis envolvidas nessa possibilidade. Por exemplo, os adultos infectados pelo HIV-1 via transmissão vertical apresentam infecção, provavelmente, desde a vida intrauterina, com exposições variáveis do uso de terapia antirretroviral, ao longo da vida, e influência de diversos fatores, como comentado anteriormente. Provavelmente, nossos pacientes constituem uma minoria do total de crianças e adolescentes infectadas pelo HIV-1 via transmissão vertical e que faleceram devido a outras complicações, antes de chegar à idade adulta. Essa complexidade fica demonstrada pela presença da maioria de participantes do presente estudo mostrarem carga viral detectável (57\%).

Esse achado contrasta com o que acontece hoje no Brasil, com os adultos infectados pelo HIV-1 via transmissão sexual, incluindo aqueles que já receberam vários esquemas antirretrovirais e precisaram de esquemas de resgate baseados em medicamentos de uso restrito. Nessa população, 83\% das PVHIV apresentam carga viral indetectável após um ano de iniciado o resgate, caindo para $72 \%, 6$ anos após ${ }^{82}$. Por tanto, a população incluída no presente estudo, parece refletir e tal vez acentuar os problemas observados em adolescentes infectados pelo HIV-1 via transmissão vertical. Nestes indivíduos, o desenvolvimento psicossocial e comportamental está influenciado pelo 
próprio HIV-1, com repercussões associadas à adesão ao tratamento antirretroviral, estigma social, condutas de risco e saúde mental ${ }^{83}$.

No presente estudo, usando os critérios de Frascati como parâmetro de classificação $^{84}$, os domínios neurocognitivos que se destacaram como comprometidos, foram os seguintes: atenção, velocidade de processamento e velocidade motora. Esses domínios neurocognitivos estão mais presentes nas alterações de tipo subcortical, como esperado em adultos infectados pelo HIV-1 via transmissão sexual ${ }^{85}$. Apesar do perfil neurológico e neurocognitivo de crianças infectadas pelo HIV-1 via transmissão vertical, ter sido considerado classicamente como diferente, em relação ao curso da doença observada em adultos, os domínios cognitivos afetados parecem ser similares ${ }^{86}$. Vale ressaltar que todos os instrumentos e baterias neuropsicológicas utilizados neste estudo foram previamente validados para a população brasileira.

Embora não existam estudos prévios que tenham avaliado o uso dos critérios diagnósticos e de classificação de Frascati em adultos infectados pelo HIV-1 via transmissão vertical, estudos recentes tem demonstrado que esses critérios podem ser aplicados em crianças e adolescentes entre 6 e 16 anos $^{87}$. Por tanto, podemos inferir que os critérios de Frascati também podem ser utilizados em adultos infectados pelo HIV-1 via transmissão vertical.

Atualmente não existe teste de triagem de escolha para avaliar HAND. 0 Questionário Neurocognitivo Breve tem sido proposto por ser sensível, mas mostra-se pouco específico na literatura. Contudo, é o teste recomendado pela guia de manejo de pacientes infectados pelo HIV-1 na Europa ${ }^{88}$. No presente estudo, os resultados obtidos no Questionário Neurocognitivo Breve, corroboraram com os resultados da avaliação neuropsicológica, sendo identificada a significância estatística na percepção subjetiva de alteração da atenção e lentificação. Esses instrumentos têm como algumas das suas funções, avaliar a capacidade do indivíduo de auto gerenciamento e independência na sua rotina diária. O Protocolo Clínico e Diretrizes Terapêuticas para Manejo da Infecção pelo HIV em Adultos, do Ministério da Saúde do Brasil, recomenda utilizar este questionário de fácil aplicação, como triagem de HAND. Nossos resultados sugerem que também parece interessante em adultos infectados pelo HIV-1 via transmissão vertical. 
Também avaliamos a IHDS, ferramenta inicialmente validada nos Estados Unidos de América e Uganda, para a triagem exclusivamente de HAD. No estudo original, a IHDS mostrou sensibilidade de $80 \%$ e especificidade de $56 \%$ para $\mathrm{HAD}^{21}$. Estudo realizado no Brasil, identificou sensibilidade de $79 \% \mathrm{e}$ especificidade de $81 \%$, utilizando a IHDS, no diagnóstico de HAD. Quando os casos de HAD foram excluídos e apenas os casos de ANI e MND foram considerados, a sensibilidade foi de apenas $46 \%{ }^{89}$. Nossos resultados confirmam estes dados, já que os resultados do IHDS foram muito similares dentre todos os grupos avaliados. Vale a pena ressaltar que no presente estudo utilizamos os valores de corte classicamente recomendados para a $\operatorname{IHDS}(\leq 10)$, é possível que utilizando valores de corte maiores $(\leq 11)$, essa ferramenta possa mostrar melhor performance, como previamente documentado ${ }^{22}$, mas mesmo assim, sua utilidade na prática clínica diária parece mais direcionada para identificar as formas mais graves de HAND.

Em relação à bateria neuropsicológica formal, as diferenças discrepantes entre os diversos grupos avaliados foram identificadas principalmente quando comparamos a forma mais grave (HAD) versus as outras categorias. Referente à atenção sustentada e atenção alternada, a análise Post Hoc mostrou diferença significativa entre a forma mais grave (HAD) e os outros. Os participantes classificados com ANI apresentaram desempenho significativamente superior ao serem comparados aos pacientes classificados com HAD quando foram avaliados em relação a velocidade de processamento de informações. $E$ os pacientes sem comprometimento cognitivo foram superiores aos pacientes com HAD quando avaliada a velocidade motora.

Diversos estudos têm sugerido associação significativa entre comprometimento neurocognitivo e algumas variáveis como maior idade, gênero

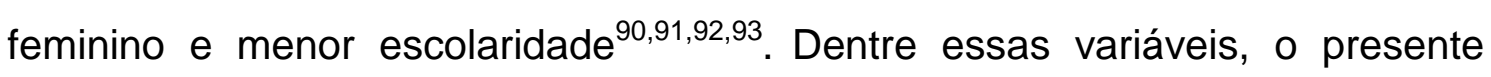
estudo apresentou alguns achados que chamaram a atenção. Os pacientes com HAD tiveram a maior média de anos de escolaridade, variável que não se traduz, necessariamente, com melhor desempenho escolar. Adicionalmente, e ainda em relação ao comentário anterior, os pacientes com HAD apresentaram a maior proporção de pessoas que declararam o lar como ocupação. Em outras 
palavras, o maior número de anos de educação formal não teve tradução em concretizar atividades trabalhista ou de estudo superior.

Em relação à análise laboratorial dos pacientes das diversas categorias avaliadas, não identificamos nenhuma variável que mostrasse diferença estatisticamente significante. Diversos estudos realizados em adultos infectados pelo HIV-1 via transmissão sexual, têm demostrado que diabetes, hipertensão e hipercolesterolemia constituem fatores de risco para o desenvolvimento de HAND $^{94,95,96,97}$. No presente estudo, os parâmetros laboratoriais foram similares nas categorias avaliadas, mas não avaliamos a presença ou ausência do diagnóstico das doenças citadas, assim como não avaliamos se os pacientes recebiam medicamentos que poderiam controlar as mesmas. Contudo, pela faixa etária estudada neste trabalho, se espera que o impacto das doenças cardiovasculares e/ou metabólicas seja menor daquele observado em pacientes adultos infectados pelo HIV-1 via transmissão sexual, principalmente aqueles em uso de tratamento antirretroviral de longa data. Contudo, pelo fato dos pacientes incluídos neste estudo apresentaram ao redor de duas décadas de infecção, é muito possível que tenham recebido antirretrovirais mais antigos e tóxicos dos usados atualmente, podem também apresentar complicações cardiovasculares e/ou metabólicas.

Em relação à depressão, neste estudo foi verificado uma frequência relativamente baixa de depressão (10.7\%), quando comparada a frequência de depressão em adultos infectados pelo HIV-1 via transmissão sexual. Por outro lado, a ocorrência de sintomas depressivos varia significativamente na presença ou ausência de sintomas relacionados à infecção pelo HIV-1, de tal forma que estima-se prevalências de depressão de $25 \%$ e $50 \%$ em pacientes assintomáticos ou sintomáticos, do ponto de visto da infecção pelo HIV-1 ${ }^{98,99}$. Estima-se que aproximadamente $22-45 \%$ dos adultos infectados pelo HIV-1 via transmissão sexual, apresentaram desordem depressiva maior em algum momento das suas vidas ${ }^{100,101}$. Contudo, a revalência que identificamos no presente estudo é maior do que relatado na população geral, de acordo com o OMS $(4,4 \%)^{102}$. Por outro lado, a prevalência identificada de depressão, em portadores de HAND, foi similar àquela descrita em portadores de doenças crônicas $(16 \%)^{36}$. 
A frequência de depressão que identificamos no presente estudo foi inferior à descrita numa metanálise recente sobre a prevalência de depressão em pacientes com comprometimento cognitivo leve, na população geral ${ }^{103}$. Nesse trabalho, a prevalência de depressão em pacientes com comprometimento leve foi de $25 \%$ em participantes da comunidade e de $40 \%$ em participantes procedentes de centros médicos, sugerindo a variabilidade da frequência de depressão em função de outras variáveis. No presente trabalho, HAD apresentou $60 \%$ de frequência de depressão, indicando que o maior comprometimento neurocognitivo se correlaciona também com a presença das queixas depressivas, as quais podem ser causadas de forma direta ou indireta pela infecção pelo HIV-1 ou, inclusive, não ter nenhuma relação com ela. Neste trabalho, somente os pacientes com HAD apresentaram sintomas de depressão (apatia, alentecimento de pensamentos, bem como, perda de interesse nas atividades e nas pessoas), chamando a atenção que esses sintomas estão presentes tanto nos quadros depressivos que se apresentam no contexto das síndromes demenciais.

Os PVHIV apresentam uma alta frequência de sintomas de depressão. Pessoas que se descobrem soropositivas passam a ter que lidar com todo o estigma que abarca o vírus. Surgem os questionamentos acerca do corpo saudável, da permanência ou não da autonomia e independência, ficam em dúvida sobre a manutenção dos vínculos sociais, afetivos e ocupacionais. Os pacientes passam a se sentir inseguros em relação a construção de planos de futuro, e de como será o julgamento social das pessoas com as quais convivem. ${ }^{96,104,105,106}$. Aqueles que hoje são adultos e que adquiriram a infecção via transmissão vertical são convocados desde o início de suas vidas a lidar com todas essas dimensões.

O presente estudo apresenta algumas limitações como, por exemplo, o tamanho da amostra, o que pressupõe que o aumento do número de pacientes reforce os resultados encontrados e até mostre novas associações ainda não encontradas. Contudo, houve muita dificuldade na inclusão dos participantes, desde o contato inicial até as recusas e não comparecimentos. Outra limitação consistiu em ter incluído pacientes de apenas um único centro, terciário e urbano. Por tanto, os resultados devem ser ponderados antes de ser extrapolados para outros cenários. 
Com relação aos diferenciais deste estudo, destaca-se a utilização de uma bateria de avaliação neuropsicológica completa, sendo muito similar àquela que se aplica para adultos infectados pelo HIV-1 via transmissão sexual. O uso de bateria neuropsicológica formal possibilita um maior alcance em relação a quantidade de funções cognitivas superiores avaliados e maior precisão na detecção das alterações cognitivas.

Como as HANDs podem progredir e se agravar, é plausível considerar que o grupo de pacientes estudados é um grupo de alto risco para apresentar alterações cognitivas que venham a interferir em suas atividades de vida diária, estudo e adesão ao tratamento. O acompanhamento neuropsicológico em conjunto com o tratamento médico poderá identificar precocemente estas alterações, com o objetivo de propor intervenções e reabilitação paralelas ao tratamento medicamentoso, com o objetivo de melhorar a qualidade de vida destes pacientes. Maiores estudos são necessários para entender melhor a população estudada neste trabalho e desenhar estratégias multidisciplinares, visando otimizar seu acompanhamento. 


\section{Conclusão}

1. Identificamos elevada frequência de HAND (82.2\%) em adultos infectados pelo HIV-1 via transmissão vertical.

2. A idade média dos participantes foi 22 anos, as mulheres representaram $53.6 \%$ da amostra e $92.8 \%$ eram solteiros. O tempo médio de educação foi de 11.3 anos. A média da contagem dos linfócitos T-CD4 dos participantes foi 500 células $/ \mathrm{mm} 3$ e $57.1 \%$ apresentou carga viral detectável.

3. A frequência de depressão foi relativamente baixa (10.7\%) na população total, mas foi elevada dentre os pacientes com HAD (60\%). 


\section{Anexos}

\section{Anexo A - Dados Demográficos e Clínicos}

- Identificação do paciente (Nro. de aleatorização).

- Sexo: ( M ) ( F )

- Idade (anos):

- Orientação Sexual:

- Naturalidade / Procedência:

- Anos completos de educação:

- Doenças sistêmicas / metabólicas prévias ou atuais (especificar):

- Doenças neuropsiquiátricas prévias ou atuais (especificar):

- Data do diagnóstico de infecção pelo HIV:

- Nadir de CD4+:

- Esquema antirretroviral atual:

- Profilaxias em uso:

- Outros medicamentos (excluindo aqueles para tratar neuropatia periférica):

- Última contagem de células CD4+ (data):

- Última quantificação da carga viral plasmática do HIV-1 (data):

- Presença de infecção pelo vírus da hepatite B ou C:

- Histórico de uso de antirretrovirais: 


\title{
Anexo B - ASSIST - Questionário para Triagem do Uso de Álcool, Tabaco e Outras Substâncias
}

\author{
TESTE DE TRIAGEM (ASSIST V3.1)DO ENVOLVIMENTO COM BEBIDAS \\ ALCOOLICAS, FUMO E FARMACOS
}

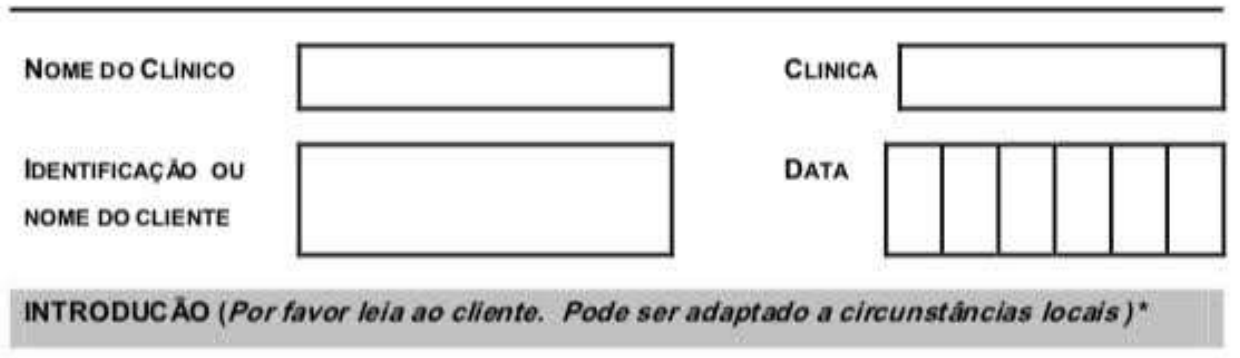

As perguntas que se seguem săo sobre a sua experiéncia quanto ao uso de alcoól, produtos de tabaco $e$ outras drogas ao longo da sua vida e nos uiltimos trés meses. Estas substancias podem ser fumadas, engolidas, aspiradas, inaladas ou injectadas (mostre o cartăo de resposta).

Alguns dos fàmacos nesta lista podem ser receitados por um médico (tal como anfetaminas. sedativos, medicamentos para dores). Para esta entrevista, aăe vamos registar medicamentos tomados conforme receitados pelo seu médico. Contudo, se tomou tais medicamentos por outras razões para além das da receita, ou se os tomou mais frequentemente, em maiores doses do que o receitado ou de um modo para os quais não foi destinado, por favor informe-me.

Embora estejamos também interessados em ter conhecimento do seu uso de várias drogas ilegais, por favor fique assegurado que a informação sobre o tal uso será tratada de um modo totalmente confidencial.

\section{NOTA: ANTES DE FAZER AS PERGUNTAS, DE AO CLIENTE OCARTAO DE RESPOSTAS ASSIST}

Pergunta 1 (por favor assinale a resposta em cada categoria de substancia)

\begin{tabular}{|c|c|c|}
\hline $\begin{array}{l}\text { Ao longo da sua vida, quais das seguintes substâncias 这 } \\
\text { usou?? (SO USO NAO-MEDICINAL) }\end{array}$ & Não & Sim \\
\hline $\begin{array}{l}\text { a. Produtos de tabaco (cigarros, tabaco para mastigar, charutos, } \\
\text { etc.) }\end{array}$ & $\square$ & $\square$ \\
\hline b. Bebidas alcoólicas (cerveja, vinho, bebidas espirituosas, etc.) & 口 & - \\
\hline c. Canabis (marijuana, ganja, erva, hash, etc.) & & $\square$ \\
\hline d. Cocaina (coke, crack, etc.) & & \\
\hline $\begin{array}{l}\text { e. Estimulantes tipo anfetamina (speed, metanfetamina, ecstasy, } \\
\text { etc.) }\end{array}$ & & \\
\hline f. Inalantes (nitroso, cola, gasolina, diluente de tinta, etc.) & & \\
\hline $\begin{array}{l}\text { g. Sedativos ou Comprimidos para Dormir (Diazepam, } \\
\text { Alprazolam, Flunitrazepam, Midazolam etc.) }\end{array}$ & & \\
\hline h. Alucinogénicos (LSD, ácido, cogumelos, trips, Ketamine, etc.) & & $\square$ \\
\hline $\begin{array}{l}\text { i. Opióides (heroina, morfina, metadona, Buprenorfina, codeina, } \\
\text { etc.) }\end{array}$ & & \\
\hline j. Outros - especifique: & 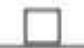 & \\
\hline
\end{tabular}

Esclareca se todas as respostas forem negativas:

"Nem mesmo quando andava na escola?"

·ASSIST V3.1 destina-se a ser usado em cenárias clinicos. Para fins de pesquisa por favour use a versbio anterior ASSIST v 3.0 o. World Health Organization (Organizaçao Mundial de Saude) 2010
Se "Năo" a todos os itens, pare a ontrevista. Se "Sim" a todos os itens, faça a Pergunta 2 sobre cada substância já usada. 


\begin{tabular}{|c|c|c|c|c|c|}
\hline $\begin{array}{l}\text { Durante os últimos três meses, quantas vezes usou as } \\
\text { substâncias que mencionou } \\
\text { (PRIMEIRA DROGA, SEGUNDA DROGA, ETC)? }\end{array}$ & $\frac{8}{5}$ & 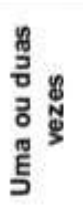 & 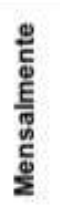 & 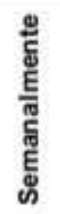 & 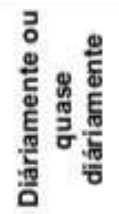 \\
\hline $\begin{array}{l}\text { a. Produtos de tabaco (cigarros, tabaco para mastigar, charutos, } \\
\text { etc.) }\end{array}$ & 0 & 2 & 3 & 4 & \\
\hline b. Bebidas alcoólicas (cerveja, vinho, bebidas espirituosas, etc.) & 0 & 2 & 3 & 4 & \\
\hline c. Canabis (marijuana, ganja, erva, hash, etc.) & 0 & 2 & 3 & 4 & \\
\hline d. Cocaina (coke, crack, etc.) & 0 & 2 & 3 & 4 & \\
\hline $\begin{array}{l}\text { e. Estimulantes tipo arfetamina (speed, metanfetamina, ecstasy, } \\
\text { etc.) }\end{array}$ & 0 & 2 & 3 & 4 & \\
\hline f. Inalantes (nitroso, cola, gasolina, diluente de tinta, etc.) & 0 & 2 & 3 & 4 & \\
\hline $\begin{array}{l}\text { g. Sedativos or Comprimidos para Dormir (Diazepam, } \\
\text { Alprazolam, Flunitrazepam, Midazolam etc.) }\end{array}$ & 0 & 2 & 3 & 4 & \\
\hline h. Alucinogénicos (LSD, ácido, cogumelos, trips, Ketamine, etc.) & 0 & 2 & 3 & 4 & \\
\hline $\begin{array}{l}\text { 1. Opióides (heroina, morfina, metadona, Buprenorfina, codeina, } \\
\text { etc.) }\end{array}$ & 0 & 2 & 3 & 4 & \\
\hline j. Outros - especifique: & 0 & 2 & 3 & 4 & \\
\hline
\end{tabular}

\section{Se "Nunca" a todos os itens na Pergunta 2, passe para a Pergunta 6.}

\section{Se quaisquer substâncias na Pergunta 2 foram usadas nos trés meses prèvios, continue com as} Perguntas 3,4 \& 5 para cada substáncia usada.

\section{Pergunta 3}

\begin{tabular}{|c|c|c|c|c|c|}
\hline $\begin{array}{l}\text { Durante os últimos três meses, quantas vezes teve um } \\
\text { desejo muito forte ou vontade de usar (PRIMEIRA DROGA, } \\
\text { SEGUNDA DROGA, ETC)? }\end{array}$ & $\begin{array}{l}\text { : } \\
\text { Ẽ } \\
z\end{array}$ & 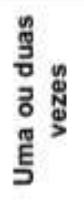 & 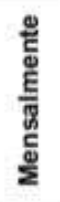 & 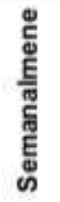 & 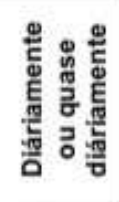 \\
\hline $\begin{array}{l}\text { a. Produtos de tabaco (cigarros, tabaco para mastigar, charutos, } \\
\text { etc.) }\end{array}$ & 0 & 3 & 4 & 5 & 6 \\
\hline b. Bebidas alcoólicas (cerveja, vinho, bebidas espirituosas, etc.) & 0 & 3 & 4 & 5 & 6 \\
\hline c. Canabis (marijuana, ganja, erva, hash, etc.) & 0 & 3 & 4 & 5 & 6 \\
\hline d. Cocaina (coke, crack, etc.) & 0 & 3 & 4 & 5 & 6 \\
\hline $\begin{array}{l}\text { e. Estimulantes tipo anfetamina (speed, metanfetamina, ecstasy, } \\
\text { etc.) }\end{array}$ & 0 & 3 & 4 & 5 & 6 \\
\hline f. Inalantes (nitroso, cola, gasolina, diluente de tinta, etc.) & 0 & 3 & 4 & 5 & 6 \\
\hline $\begin{array}{l}\text { g. Sedativos or Comprimidos para Dormir (Diazepam, } \\
\text { Alprazolam, Flunitrazepam, Midazolam etc.) }\end{array}$ & 0 & 3 & 4 & 5 & 6 \\
\hline h. Alucinogénicos (LSD, àcido, cogumelos, trips, Ketamine, etc.) & 0 & 3 & 4 & 5 & 6 \\
\hline $\begin{array}{l}\text { 1. Opióides (heroina, morfina, metadona, Buprenorfina, codeina, } \\
\text { etc.) }\end{array}$ & 0 & 3 & 4 & 5 & 6 \\
\hline j. Outros - especifique: & 0 & 3 & 4 & 5 & 6 \\
\hline
\end{tabular}




\begin{tabular}{|c|c|c|c|c|c|}
\hline $\begin{array}{l}\text { Durante os últimos três meses, quantas vezes o uso de } \\
\text { (PRIMEIRA DROGA, SEGUNDA DROGA, ETC)? o levou a } \\
\text { problemas de saúde, sociais, legais ou financeiros? }\end{array}$ & 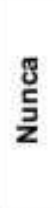 & 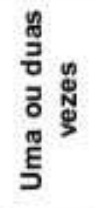 & 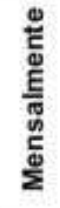 & 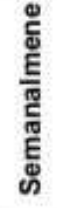 & 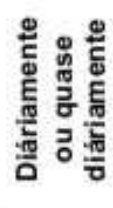 \\
\hline $\begin{array}{l}\text { a. Produtos de tabaco (cigarros, tabaco para mastigar, charutos, } \\
\text { etc.) }\end{array}$ & 0 & 4 & 5 & 6 & 7 \\
\hline b. Bebidas alcoólicas (cerveja, vinho, bebidas espirituosas, etc.) & 0 & 4 & 5 & 6 & 7 \\
\hline c. Canabis (marijuana, ganja, erva, hash, etc.) & 0 & 4 & 5 & 6 & 7 \\
\hline d. Cocaina (coke, crack, etc.) & 0 & 4 & 5 & 6 & 7 \\
\hline $\begin{array}{l}\text { e. Estimulantes tipo anfetamina (speed, metanfetamina, ecstasy, } \\
\text { etc.) }\end{array}$ & 0 & 4 & 5 & 6 & 7 \\
\hline f. Inalantes (nitroso, cola, gasolina, diluente de tinta, etc.) & 0 & 4 & 5 & 6 & 7 \\
\hline $\begin{array}{l}\text { g. Sedativos or Comprimidos para Dormir (Diazepam, } \\
\text { Alprazolam, Flunitrazepam, Midazolam etc.) }\end{array}$ & 0 & 4 & 5 & 6 & 7 \\
\hline h. Alucinogénicos (LSD, ácido, cogumelos, trips, Ketamine, etc.) & 0 & 4 & 5 & 6 & 7 \\
\hline $\begin{array}{l}\text { i. Opióides (heroina, morfina, metadona, Buprenorfina, codeina, } \\
\text { etc.) }\end{array}$ & 0 & 4 & 5 & 6 & 7 \\
\hline j. Outros - especifique: & 0 & 4 & 5 & 6 & 7 \\
\hline
\end{tabular}

\section{Pergunta 5}

\begin{tabular}{|l|l|l|l|l|}
\hline $\begin{array}{l}\text { Nos últimes três meses, quantas vezes não fez aquilo que } \\
\text { era normalmente se esperaria de si devido ao uso de } \\
\text { (PRIMEIRA DROGA, SEGUNDA DROGA, ETC)? }\end{array}$ & &
\end{tabular}


Faça as Perguntas 6 \& 7 sobre todas as substâncias jamais usadas (i.e. as referidas na Pergunta 1)

\section{Pergunta 6}

\begin{tabular}{|c|c|c|c|}
\hline $\begin{array}{l}\text { Já algum amigo ou familiar ou qualquer outra pessoa } \\
\text { expressou uma preocupação com o seu uso de } \\
\text { (PRIMEIRA DROGA, SEGUNDA DROGA, ETC.)? }\end{array}$ & 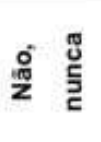 & 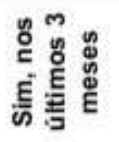 & 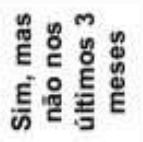 \\
\hline $\begin{array}{l}\text { a. Produtos de tabaco (cigarros, tabaco para mastigar, charutos, } \\
\text { etc.) }\end{array}$ & 0 & 6 & 3 \\
\hline b. Bebidas alcoólicas (cerveja, vinho, bebidas espirituosas, etc.) & 0 & 6 & 3 \\
\hline c. Canabis-(marijuana, ganja, erva, hash, etc.) & 0 & 6 & 3 \\
\hline d. Cocaina (coke, crack, etc.) & 0 & 6 & 3 \\
\hline $\begin{array}{l}\text { e. Estimulantes tipo anfetamina (speed, metanfetamina, ecstasy, } \\
\text { etc.) }\end{array}$ & 0 & 6 & 3 \\
\hline f. Inalantes (nitroso, cola, gasolina, diluente de tinta, etc.) & 0 & 6 & 3 \\
\hline $\begin{array}{l}\text { g. Sedativos or Comprimidos para Dormir (Diazepam, } \\
\text { Alprazolam, Flunitrazepam, Midazolam etc.) }\end{array}$ & 0 & 6 & 3 \\
\hline h. Alucinogénicos (LSD, ácido, cogumelos, trips, Ketamine, etc.) & 0 & 6 & 3 \\
\hline $\begin{array}{l}\text { i. Opióides (heroina, morfina, metadona, Buprenorfina, codeina, } \\
\text { etc.) }\end{array}$ & 0 & 6 & 3 \\
\hline 1. Outros - especifique: & 0 & 6 & 3 \\
\hline
\end{tabular}

\section{Pergunta 7}

\begin{tabular}{|c|c|c|c|}
\hline $\begin{array}{l}\text { Jả algum dia experimentou diminuir o uso de (PRIMEIRA } \\
\text { DROGA, SEGUNDA DROGA,ETC.) mas não conseguiu? }\end{array}$ & $\begin{array}{ll}0 \\
\text { 일 } \\
\text { Z }\end{array}$ & 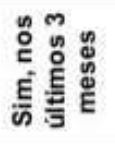 & 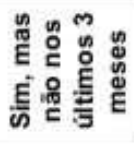 \\
\hline $\begin{array}{l}\text { a. Produtos de tabaco (cigarros, tabaco para mastigar, charutos, } \\
\text { etc.) }\end{array}$ & 0 & 6 & 3 \\
\hline b. Bebidas alcoólicas (cerveja, vinho, bebidas espirituosas, etc.) & 0 & 6 & 3 \\
\hline c Canabis (marijuana, ganja, erva, hash, etc.) & 0 & 6 & 3 \\
\hline d. Cocaina (coke, crack, etc.) & 0 & 6 & 3 \\
\hline $\begin{array}{l}\text { e. Estimulantes tipo anfetamina (speed, metanfetamina, ecstasy, } \\
\text { etc.) }\end{array}$ & 0 & 6 & 3 \\
\hline f. Inalantes (nitroso, cola, gasolina, diluente de tinta, etc.) & 0 & 6 & 3 \\
\hline $\begin{array}{l}\text { g. Sedativos or Comprimidos para Dormir (Diazepam, Alprazolam, } \\
\text { Flunitrazepam, Midazolam etc.) }\end{array}$ & 0 & 6 & 3 \\
\hline h. Alucinogénicos (LSD, ácido, cogumelos, trips, Ketamine, etc.) & 0 & 6 & 3 \\
\hline $\begin{array}{l}\text { 1. Opióides (heroina, morfina, metadona, Buprenorfina, codeina, } \\
\text { etc.) }\end{array}$ & 0 & 6 & 3 \\
\hline j. Outros-especifique: & 0 & 6 & 3 \\
\hline
\end{tabular}


Pergunta 8 (por favor assinale a resposta)

\begin{tabular}{|c|c|c|c|}
\hline & 完 & 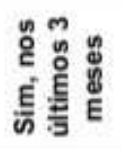 & 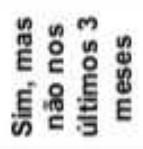 \\
\hline $\begin{array}{l}\text { Já agum dia injectou drogas? } \\
\text { (SO USO NÃO-MEDICINAL) }\end{array}$ & & & \\
\hline
\end{tabular}

\section{NOTA IMPORTANTE:}

Deve-se perguntar aos clientes que se injectaram com drogas nos últimos très meses o padrăo de injecçăo durante este periodo, para determiner os niveis de risco e o melhor percurso para a intervençăo.

PADRAO DE INTERVENÇĀO

DIRECTRIZES PARA

\section{INTERVENÇÃO}

4 dias por mês, em média, nos

Intervençăo breve incluíndo o cartăo

últimos três meses ou menos

de "Riscos de intervencão"

Mais do que 4 dias por mês em

Continuaçâo da avaliaçăo e mais

média, ao longo dos útimos 3 mêses

trat amento intensivo*

\section{COMO CALCULAR OS VALORES DE ENVOLVIMENTO COM UMA SUBSTÃNCIA ESPECIFICA}

Para cada substância (marcada de a. a j.) adicionar os valores recebidos da pergunta 2 até, e incluindo, a 7. Năo incluir nestes valores os resultados da $\mathrm{P} 1$ ou P8. Por exemplo, os valores para canabis seriam calculados assim: $\mathbf{P} 2 \mathrm{c}+\mathbf{P} 3 \mathrm{c}+\mathbf{P} 4 \mathrm{c}+\mathbf{P} 5 \mathrm{c}+\mathbf{P} 6 \mathrm{c}+\mathbf{P} 7 \mathrm{c}$

Note que P5 para tabaco nâo está codificada, e é calculada assim: P2a + P3a + P4a + P6a + P7a

O TIPO DE INTERVENÇAO É DETERMINADO PELO VAL OR DE ENVOLVIMENTO DO PACIENTE COM UMA SUBSTANCIA ESPECIFICA

\begin{tabular}{|l|c|c|c|c|}
\hline & $\begin{array}{c}\text { Registar o valor } \\
\text { especifico da } \\
\text { substância }\end{array}$ & $\begin{array}{c}\text { nâo } \\
\text { intervençăo }\end{array}$ & $\begin{array}{c}\text { receber uma } \\
\text { breve intervenção }\end{array}$ & $\begin{array}{c}\text { tratamento mais } \\
\text { intensivo * }\end{array}$ \\
\hline a. tabaco & $0-3$ & $4-26$ & $27+$ \\
\hline b. alcoól & $0-10$ & $11-26$ & $27+$ \\
\hline c. canabis & $0-3$ & $4-26$ & $27+$ \\
\hline d. cocaína & $0-3$ & $4-26$ & $27+$ \\
\hline e. anfetamina & $0-3$ & $4-26$ & $27+$ \\
\hline f. inalantes & $0-3$ & $4-26$ & $27+$ \\
\hline g. sedativos & & $0-3$ & $4-26$ & $27+$ \\
\hline h. alucinogénicos & & $0-3$ & $4-26$ & $27+$ \\
\hline i. opióides & $0-3$ & $4-26$ & $27+$ \\
\hline j. outras drogas & & $0-3$ & $4-26$ & \\
\hline
\end{tabular}

Agora use o CARTÃO DE RELATORIO DA AVALIAÇĂO ASSIST para fazer ur intervenção breve ao cliente. 


\section{Anexo C - HAD - Escala de Depressão e Ansiedade Hospitalar}

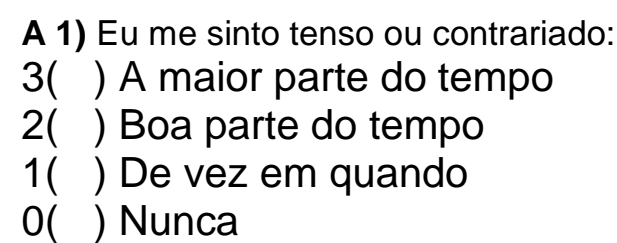

D 2) Eu ainda sinto gosto pelas mesmas coisas de antes:

0 ( ) Sim, do mesmo jeito que antes

1( ) Não tanto quanto antes

2( ) Só um pouco

3( ) Já não sinto mais prazer em nada

A 3) Eu sinto uma espécie de medo, como se alguma coisa ruim fosse acontecer:

3( ) Sim, e de um jeito muito forte

2( ) Sim, mas não tão forte

1( )Um pouco, mas isso não me preocupa

O( ) Não sinto nada disso

D 4) Dou risada e me divirto quando vejo coisas engraçadas:

0( ) Do mesmo jeito que antes

1( ) Atualmente um pouco menos

2( ) Atualmente bem menos

3( ) Não consigo mais

A 5) Estou com a cabeça cheia de preocupações:

3( ) A maior parte do tempo

2( ) Boa parte do tempo

1( ) De vez em quando

0( ) Raramente

D 6) Eu me sinto alegre:

3( ) Nunca

2( ) Poucas vezes

1( ) Muitas vezes

o( ) A maior parte do tempo

A 7) Consigo ficar sentado à vontade e me sentir relaxado?

0( ) Sim, quase sempre

1( ) Muitas vezes

2( ) Poucas vezes

3( ) Nunca 
D 8) Eu estou lento para pensar e fazer as coisas:

3( ) Quase sempre

2( ) Muitas vezes

1( ) De vez em quando

O( ) Nunca

A 9) Eu tenho uma sensação ruim de medo, como um frio na barriga ou um aperto no estômago:

0 ( ) Nunca

1( ) De vez em quando

2( ) Muitas vezes

3( ) Quase sempre

D 10) Eu perdi o interesse de cuidar de minha aparência:

3( ) Completamente

2( ) Não estou mais me cuidando como eu deveria

1( ) Talvez não tanto quanto antes

0 ( ) Me cuido do mesmo jeito que antes

A 11) Eu me sinto inquieto, como se eu não pudesse ficar parado em lugar nenhum:

3( ) Sim, demais

2( ) Bastante

1( ) Um pouco

O( ) Não me sinto assim

D 12) Fico esperando animado as coisas boas que estão por vir:

0 ( ) Do mesmo jeito que antes

1( ) Um pouco menos do que antes

2( ) Bem menos do que antes

3( ) Quase nunca

A 13) De repente, tenho a sensação de entrar em pânico:

3( ) A quase todo momento

2( ) Várias vezes

1( ) De vez em quando

0 ( ) Não sinto isso

D 14) Consigo sentir prazer quando assisto um bom programa de televisão, de rádio, ou quando leio alguma coisa:

0( ) Quase sempre

1( ) Várias vezes

2( ) Poucas vezes

3( ) Quase nunca 


\section{Anexo D - Questionário Neurocognitivo Breve}

1. Memória: Você tem perda de memória frequente? Se esquece de eventos especiais ou reuniões, inclusive aquelas mais recentes?":

(sim, definitivamente) (sim, às vezes) (não)

2. Lentificação psicomotora: Você sente que você está mais lento quando pensa, planeja atividades ou resolve problemas?":

(sim, definitivamente) (sim, às vezes) (não)

3. Atenção: Você tem dificuldades para prestar atenção durante uma conversa, ler um jornal ou assistir um filme?

(sim, definitivamente) (sim, às vezes) (não) 


\section{Anexo E - Escala Instrumental para Atividades da Vida Diária Lawton. Adaptado de: Lopes dos Santos e Virtuoso Junior, 2008.}

[A] Em relação ao uso de telefone:

$3=$ recebe e faz ligações sem assistência

2 = necessita de assistência para realizar ligações telefônicas

1 = não tem o hábito ou é incapaz de usar o telefone

[B] Em relação às viagens:

$3=$ realiza viagens sozinho

2 =somente viaja quando tem companhia

1 = não tem o hábito ou é incapaz de usar de viajar

[C] Em relação à realização de compras:

3 = realiza compras quando é fornecido transporte

2 = somente faz compras quando tem companhia

1 = não tem o hábito ou é incapaz de realizar compras

[D] Em relação ao preparo de refeições

3 = planeja e cozinha as refeições completas

2 = prepara somente refeições pequenas ou quando tem ajuda

1 = não tem o hábito ou é incapaz de preparar refeições

[E] Em relação ao trabalho doméstico

$3=$ realiza tarefas pessadas

2 = realiza tarefas leves, precisando de ajuda nas pesadas

1 = não tem o hábito ou é incapaz de realizar trabalhos domésticos

[F] Em relação ao uso de medicamentos

3 = faz uso de medicamentos sem assistência

2 = necessita de lembretes ou de assistência

1 = é incapaz de controlar sozinho o uso de medicamentos

[G] Em relação ao manuseio de dinheiro

3 = paga contas sem auxilio

2 = necessita de assistência para o pagar contas

1 = não tem o hábito de lidar com dinheiro ou é incapaz de manusear dinheiro, contas

\section{Pontuação Total:}

Interpretação da Escala Instrumental para Atividades da Vida Diária. $O$ escore final consiste na somatória dos itens A-G. O máximo escore possível é de 21 pontos. Classificação: 1) Dependência total $\leq 7$; 2) Dependência parcial: $>7$ até < 21; Independência: 21. Para pacientes que usualmente não realizam as atividades dos itens $D-E$, considerar o máximo escore possível de 15 e usar a seguinte classificação: 1 ) Dependência total $\leq 5$; 2) Dependência parcial: $>5$ até < 15; Independência: 15. 


\section{ANEXO F - International HIV Dementia Scale. Adaptado de: Sackor e colaboradores, 2005.}

Registro de memória: Mencionar 4 palavras que o pacientes deverá recordar (cão, chapéu, feijão, vermelho). Apresentar cada palavra em 1 segundo. Depois, peça para o paciente repetir as 4 palavras que você acabou de mencionar. Repita as palavras que o paciente não lembrou imediatamente. Explique ao paciente que você perguntará por essas palavras alguns minutos depois.

1. Rapidez motora: Solicite que o paciente bata os dois primeiros dedos da mão não dominante tão ampla e rapidamente como seja possível. Pontuação:

$4=15$ em 5 segundos

$3=11-14$ em 5 segundos

$2=7-10$ em 5 segundos

$1=3-6$ em 5 segundos

$0=0-2$ em 5 segundos

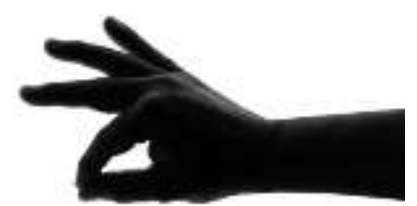

2. Rapidez psicomotora: $O$ paciente deverá realizar os seguintes movimentos com a mão não dominante tão rápido como seja possível: 1) Apertar a mão em punho sobre uma superfície plana, 2) Colocar a mão sobre uma superfície plana com a palma para baixo, e 3) Colocar a mão perpendicular à superfície plana sobre o lado do quinto dedo. Demonstrar e solicitar que o paciente pratique duas vezes esses movimentos.

Pontuação:

4 = 4 sequências em 10 segundos

$3=3$ sequências em 10 segundos

2 = 2 sequências em 10 segundos

1 = 1 sequência em 10 segundos

0 = incapaz de realizar
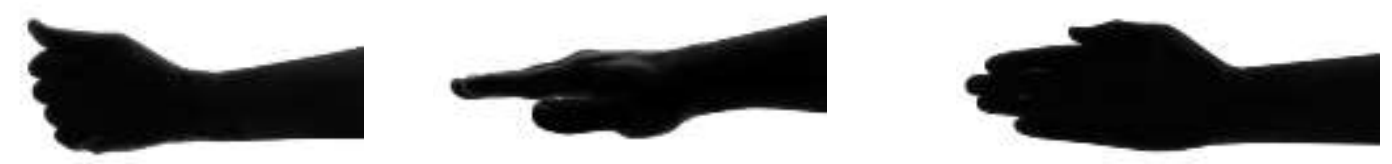

3. Memória: perguntar ao paciente pelas 4 palavras mencionadas ao início desta parte da avaliação. Para as palavras não recordadas, mencionar uma clave semântica, por exemplo: animal (cão), peça de roupa (chapéu), alimento (feijão), cor (vermelho). Dar 1 ponto para cada palavra lembrada espontaneamente. Dar 0.5 ponto para cada palavra lembrada após a clave semântica. Máximo $=4$ pontos

Pontuação Total: 
Interpretação da International HIV Dementia Scale: O escore final consiste na somatória dos itens 1-3. O máximo escore possível é de 12 pontos. Pacientes com pontuações menores ou iguais a 10 devem ser considerados para investigação de HAND. 
ANEXO G - Trail Making Test A and B

TESTE DE TRILHAS

Parte A

Exemplo

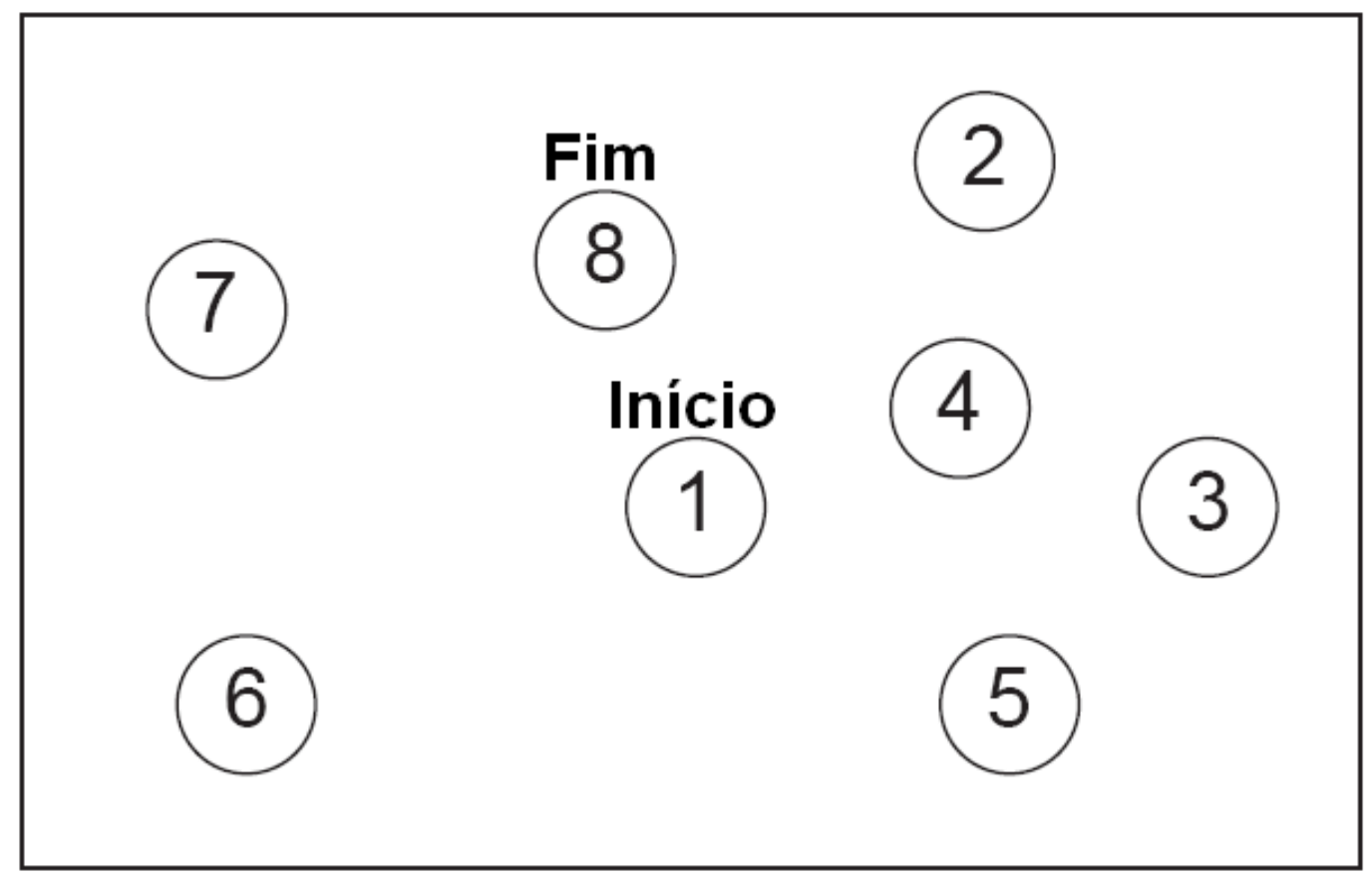


(15)

(17)

(21)

(20)

(19)

(16)

18

(5)

(4) 22

(13)

(6)

(7)

Begin

14

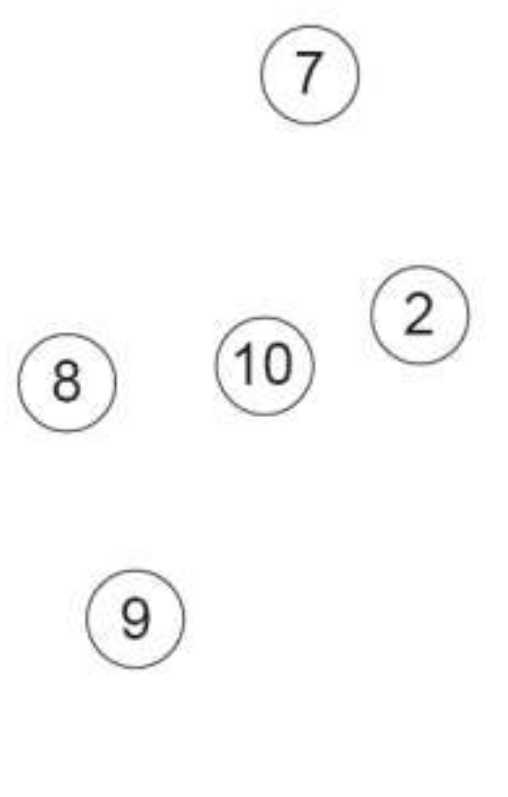

(12)

(11) 25

(23)

Fim 
TESTE DE TRILHAS

Parte B

Exemplo

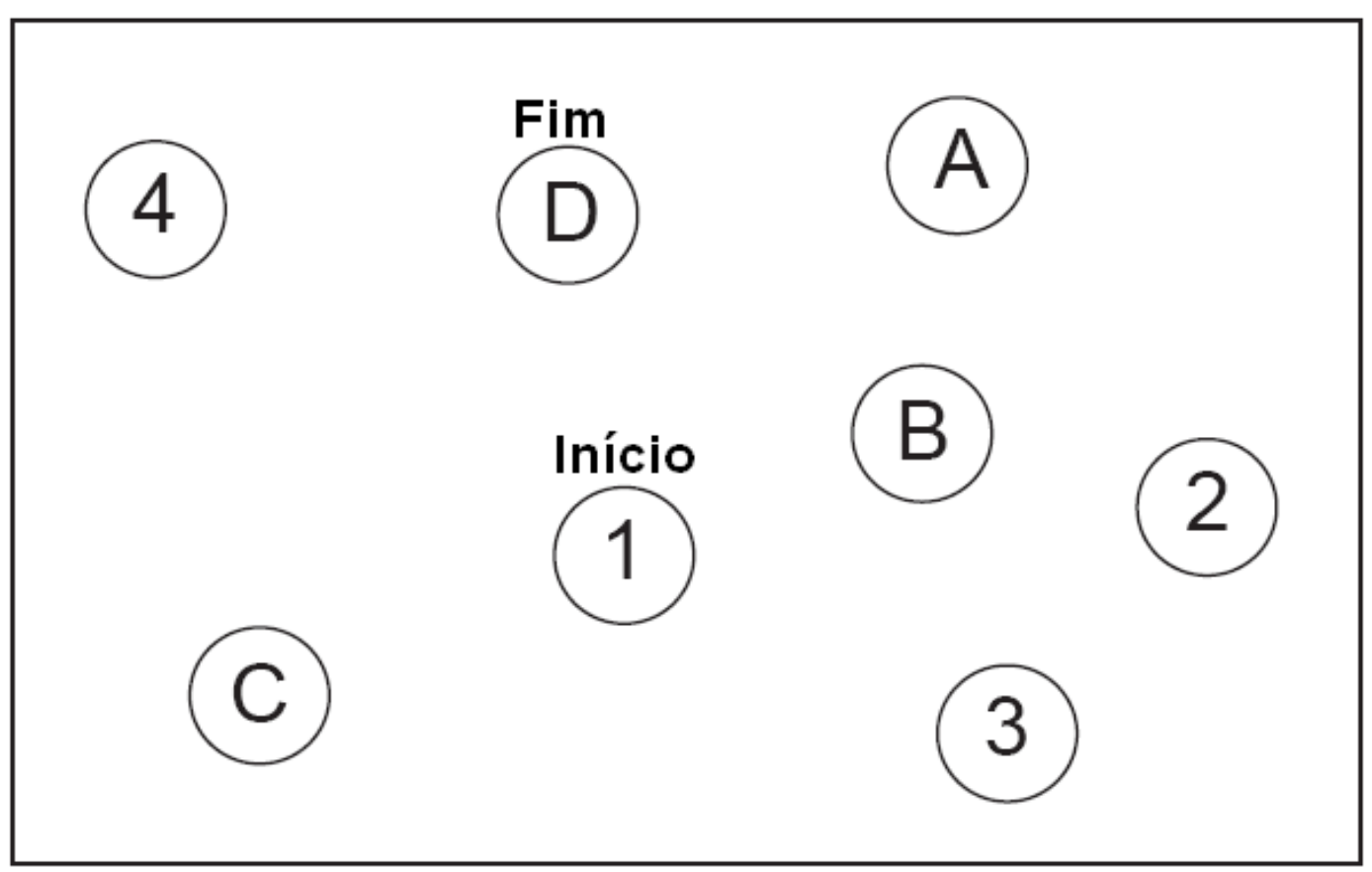


(13)

(8)

(9)

(B) 4

(3)

(7)

(H)

(12)

G)

(A)

(5)

(10)

(I) (D)

(C)

(6)

F

(2)

(L)

K)

11)

(E)

(J) 


\section{ANEXO H - Termo de Consentimento Livre e Esclarecido (TCLE)}

TERMO DE CONSENTIMENTO LIVRE E ESCLARECIDO

Dados de identificação do sujeito da pesquisa ou responsável legal

Nome:

Documento de Identidade $\mathrm{N}^{\mathrm{o}}$ :

Data de nascimento:

Endereço.

Bairro:
Sexo: $M($ ) $F(~)$

Idade:

............... .complemento...

Cidade:

Telefone: Celular:

Responsável

Legal.

Natureza (grau de parentesco, tutor, curador

etc.).....

Documento de Identidade $\mathrm{N}^{\circ}$ : Sexo: $M($ ) $F(~)$

Data de nascimento: Idade:

Endereço

Bairro:

Cidade: .complemento... $\mathrm{N}^{\mathrm{o}}$

CEP:

Telefone: Celular:

\section{DADOS SOBRE A PESQUISA:}

Título do protocolo de pesquisa: :FREQUÊNCIA DAS ALTERAÇÕES NEUROCOGNITIVAS ASSOCIADAS AO HIV EM ADULTOS INFECTADOS POR TRANSMISSÃO VERTICAL".

Pesquisador: Sarah Moura Silvany

Cargo/função: Psicóloga

Inscrição no Conselho Regional de Psicologia: 06/118835

Orientador: José Ernesto Vidal Bermudez

Cargo/função: Médico

Unidade do HCFMUSP: SEAP - Serviço de Extensão ao Atendimento HIV/AIDS da

Divisão de Moléstias Infecciosas e Parasitárias do Instituto Central do Hospital das

Clínicas

Co-orientador: Angela Carvalho Freitas

Cargo/função: Médica 
Unidade do HCFMUSP: SEAP - Serviço de Extensão ao Atendimento HIV/AIDS da Divisão de Moléstias Infecciosas e Parasitárias do Instituto Central do Hospital das Clínicas

Colaborador: Maria Rita Polo Gascón

Cargo/função: Psicóloga

Unidade do HCFMUSP: Divisão de Psicologia do ICHC

\section{Avaliação do risco da Pesquisa:}

Risco mínimo (x) Risco médio ( )

Risco baixo ( ) Risco maior ( )

Duração da Pesquisa: 2 anos

Rubrica do sujeito de pesquisa ou responsável:

Rubrica do pesquisador:

\section{HOSPITAL DAS CLÍNICAS DA FACULDADE DE MEDICINA DA UNIVERSIDADE DE SÃO PAULO-HCFMUSP}

Você está sendo convidado a participar de uma pesquisa intitulada: "Frequência das alterações neurocognitivas associadas ao HIV em adultos infectados por transmissão verticaL". Sua participação é muito importante para que possamos investigar se o vírus HIV está afetado suas funções cognitivas, como memória, atenção e raciocinio. Caso sejam identificados alguns destes aspectos, você terá acesso a todo o apoio necessário por parte da equipe multidisciplinar, se assim o desejar.

Sua participação é completamente voluntária e você é livre para recusar caso não se sinta à vontade para participar.

Caso você opte por participar, a pesquisa consistirá na realização de uma entrevista e aplicação dos seguintes instrumentos:

1) A entrevista contém questões sobre dados demográficos e clínicos como sexo, idade, orientação sexual, data do diagnóstico da infecção pelo HIV, mecanismo de transmissão da infecção, uso de álcool e outras substâncias psicoativas; dados clínicos: uso atual e histórico de antirretrovirais; dados laboratoriais: contagem de linfócitos CD4+ e quantificação da carga viral do HIV-1. Serão considerados os resultados laboratoriais mais próximos à avaliação clínica (até 3 meses antes);

2) A Escala Hospitalar de Ansiedade e Depressão (HAD) possui 14 itens de múltipla escolha, dos quais sete são voltados para a avaliação da ansiedade e sete para a depressão.

3) Questionário para avaliar as atividades de vida diária - Escala de Lawton e Brody, são 7 perguntas para saber se você consegue fazer sozinho ou precisa de ajuda em atividades do dia como usar o telefone, fazer comida; 
4) Questionário de rastreio de alterações neurocognitivas em pacientes infectados por HIV-1 - International HIV Dementia Scale (IHDS) onde será pedido que você memorize algumas palavras e faça movimentos com as mãos para verificar o quão rápido você é;

5) Bateria de testes neuropsicológicos, onde você terá que memorizar palavras e números, fazer um desenho e depois de recordar dele, dar o significado de algumas palavras, dizer qual parte completa uma figura, ligar o mais rápido possível números e letras em ordem crescente, encaixar pinos em buracos, dizer o mais rápido palavras que comecem com determinada letra.

6) ASSIST - escala com perguntas para saber se você usa ou usou algum tipo de droga, como maconha ou cigarro.

A aplicação dos questionários acontecerá no SEAP - Serviço de Extensão ao Atendimento HIV/AIDS da Divisão de Moléstias Infecciosas e Parasitárias do Instituto Central do Hospital das Clínicas, com duração de, aproximadamente, de 90 minutos. A pesquisa apresenta risco mínimo aos participantes, ou seja, você pode ficar cansado durante a aplicação dos testes. Caso isso ocorra, por favor, avise o avaliador.

O dia e horário para a realização das atividades acima será combinado anteriormente com você e, caso queira desistir da pesquisa a qualquer momento, você não será prejudicado nos atendimentos em qualquer serviço deste hospital.

Caso haja alguma dúvida, durante qualquer etapa do estudo, sinta-se à vontade para falar conosco entrando em contato com a pesquisadora principal pelo número de telefone: (11) 98104-2733 - Sarah. Se você tiver alguma consideração ou dúvida sobre a ética da pesquisa, entre em contato com o Comitê de Ética em Pesquisa (CEP) - Rua Ovídio Pires de Campos, 225 - 50 andar - tel: 2661-6442 ramais 16, 17, 18 - e-mail: cappesq@hcnet.usp.br.

É garantida a liberdade da retirada de consentimento a qualquer momento e deixar de participar do estudo, sem qualquer prejuízo à continuidade de seu tratamento na Instituição.

As informações obtidas serão analisadas em conjunto com outros pacientes, não sendo divulgado a identificação de nenhum paciente;

Não há despesas pessoais para o participante em qualquer fase do estudo, incluindo exames e consultas. Também não há compensação financeira relacionada à sua participação.

Rubrica do sujeito de pesquisa ou responsável:

Rubrica do pesquisador:

Rubrica do orientador: 


\section{HOSPITAL DAS CLÍNICAS DA FACULDADE DE MEDICINA DA UNIVERSIDADE DE SÃO PAULO-HCFMUSP}

$\mathrm{Eu}$,

li este

Termo de consentimento e conversei com o os pesquisadores sobre a minha decisão em participar nesse estudo. Ficaram claros para mim quais são os propósitos do estudo, os procedimentos a serem realizados, seus desconfortos e riscos, as garantias de confidencialidade e de esclarecimentos permanentes. Ficou claro também que minha participação é isenta de despesas e que tenho garantia do acesso a tratamento hospitalar quando necessário. Concordo voluntariamente em participar deste estudo e poderei retirar o meu consentimento a qualquer momento, antes ou durante o mesmo, sem penalidades ou prejuízo ou perda de qualquer benefício que eu possa ter adquirido, ou no meu atendimento neste Serviço. Confirmo que recebi 1 (uma) cópia do presente termo de consentimento.

Assinatura do paciente ou representante legal Data

Declaro que obtive de forma apropriada e voluntária o Consentimento Livre e Esclarecido deste paciente ou representante legal para a participação neste estudo.

Assinatura do pesquisador Data _ I__

Assinatura do orientador

Data 


\section{Referências}

1. Centers for Disease Control and Prevention. Pneumocystis Pneumonia --Los Angeles. MMWR 1981;30:1-3

2. Petri, Valéria Petri, da Escola Paulista de Medicina

3. Vermelho, Silva e Costa, 1999 5. Vermelho LL, Silva LP, Costa AJL. Epidemiologia da transmissão vertical do HIV no Brasil. Boletim Epidemiológico - Aids. 1999;12(3):5-15.

4. Organização Mundial da Saúde - OMS, 2016.

5. UNAIDS, 2014

6. UNAIDS Brasil. Prevention Gap Report. [Online].; 2016 [cited 2017 January. Available from:

http://www.unaids.org/en/resources/documents/2016/prevention-gap.).

7. Van Rie, Harrington, Dowe \& Robertson, 2007 https://www.ncbi.nlm.nih.gov/pubmed/17137813.

8. Plowfield L. A. HIV disease in children 25 years later. Pediatric Nursing 33 , 273- 278.). 2007.

9. Lawrence DM, Major EO. HIV-1 and the brain: connections between HIV-1associated dementia, neuropathology and neuroimmunology. Microbes Infect. 2002,4:301-8).

10. Clifford DB. AIDS dementia. Med Clin North Am. 2002;86:537-50.

11. Everall IP, Luthert PJ, Lantos PL. Neuronal loss in the frontal cortex in HIV infection. Lancet. 1991;337(8750):1119-21. 
12 Bell JE An update on the neuropathology of HIV in the HAART era. Histopathology. 2004;45:549-59).

13. Navia BA, Dafni U, Simpson D, et al. (1998) A phase $I / I$ trial of nimodipine for HIV-related neurologic complications. Neurology; 51:221-228.

14. Guerra, C. P. P. and SEIDL, E. M. F.. Crianças e adolescentes com HIV/aids: revisão de estudos sobre revelação do diagnóstico, adesão e estigma. Paidéia (Ribeirão Preto) [online]. 2009, vol.19, n.42

15. Price, R.W. Text Book of aids Medicine In: Merigan, T.E.; Bartlett, J.G.; Bolognesi D.. 2nd Ed. Baltimore, Willians \& Wilkins,477-97, 1998

16. Fuentes D et al. Neuropsicologia: Teoria e Prática. 2a ed. Porto Alegre: Artmed; 2013. 432p.

17. (UNAIDS. Global Aids Update. [Online].; 2016 [cited 2017 January. Available from: http://www.unaids.org/sites/default/files/media_asset/globalAIDS-update2016_en.pdf

18. Ellis $\mathrm{R} \mathrm{J}$ et al. Randomized Trial of Central Nervous System-Targeted Antiretrovirals for HIV-Associated Neurocognitive Disorder. Clin Infect Dis. $2014 ; 7: 1015-22)$.

19. Lancet Neurol. 2014;13(11):1139-51.

20. Sheppard DP et al. Random Number Generation in HIV Disease: Associations with Neuropsychological Functions and Activities of Daily Living. Arch Clin Neuropsychol. 2017;32(1):53-62.

21. Ellis RJ, Evans SR, Clifford DB, Moo LR, McArthur JC, Collier AC et. al. Clinical validation of the NeuroScreen. J Neurovirol 2005 Dec; 11 (6): p. 503-11.

22. Alexopoulos GS et al. Clinical presentation of the depression executive dysfunction syndrome of late life. American Journal of Geriatric Psychiatry. 2002;10(1):98-106.). 
23. Lima MCC. Prevalência de alterações neurocognitivas associadas ao HIV em uma coorte aderente ao antirretroviral em um hospital geral na cidade de São Paulo [Dissertação]. São Paulo: Faculdade de Medicina, Universidade de São Paulo; 2017.

24.http://www.scielo.br/scielo.php?script=sci_arttext\&pid=S141449802014000200196

25. https://www.liebertpub.com/doi/abs/10.1089/apc.2017.0202?journalCode=apc

26.Tsegaw M, Andargie G, Alem G, Tareke M. Screening HIV-associated neurocognitive disorders (HAND) among HIV positive patients attending antiretroviral therapy in South Wollo, Ethiopia. J Psychiatr Res. 2017;85:37-41.

27. Thaler NS et al. Interactive effects of neurocognitive impairment and substance use on antiretroviral non-adherence in HIV disease. Arch Clin Neuropsychol. 2015;30(2):114-21.).

28. Antinori A et al. Updated research nosology for HIV-associated neurocognitive disorders. Neurology. 2007;69(18):1789-99.).

29. McArthur, J.C. HIV dementia: an evolving disease. J Neuroimmunol 2004;157:3- J Neuroimmunol. 2004; 157(1-2):3-10).

30. Brew, B.J. Evidence for a change in AIDS dementia complex in the era of highly active antiretroviral therapy and the possibility of new forms of AIDS dementia complex. aids,18(suppl 1): S75-78, 2004. Recuperado em 06 de janeiro de 2016:www.journals.Iww.com

31. Capel V.A.; Sá M.A.C.; Norma P Rubini P. N.; Kalil S. R.; Miranda5 E.(2006) The influence Of neuro-AIDS in Children J. bras Doenças Sex Transm 18 (4): 259-262)

32. Christo, P. P.. (2010). Alterações cognitivas na infecção pelo HIV e Aids. Revista da Associação Médica Brasileira, 56(2), 242-247. Retrieved June 17, 2015, from http://www.scielo.br/scielo.php?script=sci arttext\&pid=S0104$\underline{42302010000200027 \& \operatorname{lng}=e n \& \text { tIng=pt. }}$ 
33. Dubé B, Benton T, Cruess DE, Evans DL. Neuropsychiatric manifestations of HIV infection and AIDS. J Psychiatry Neurosci. 2005;30:237-46.

34. Heaton RK, Grant I, Butters N, White DA, Kirson D, Atkinson JH, et al. The HNRC 500-neuropsychology of HIV infection at different disease stages. J Int Neuropsychol Soc. 1995;1:231-51)

35. https://www.ncbi.nlm.nih.gov/pubmed/8507418/). Comumente estas manifestações se fazem presentes por conta da queda da contagem dos linfócitos T-CD4

36. http://www.bibliotecadigital.ufmg.br/dspace/handle/1843/ECJS-84SGEV

37. https://www.cdc.gov/mmwr/preview/mmwrhtml/00032890.htm

38. Belman, A. L. Acquired Immunodeficiency Syndrome And The Child's Central Nervous System. Pediatrneurol, V.39, P.691-714, 1992.

39. Tellechea-Rotta N, Legido A. Acquired immunodeficiency syndrome by vertical transmission:neurological disorders. Rev Neurol, v.36, p.1-15, 2003

40. Bruck I, Tahan TT, Cruz CR, et al. Developmental milestones of vertically HIV infected and seroreverters children. Follow-up of 83 children. Arq Neuropsiquiatr 2001;59:691-695.

41. TELLECHEA-ROTTA N, Legido A. Acquired immunodeficiency syndrome by vertical transmission: neurological disorders. Rev Neurol 2003; 36:256-263.).

42. Tardieu, M; Mayaux, M-J; Seibel, N.; Funck-Brentano, I.; Straub, E.; Teglas, J.P.; Blanche, S. Cognitive assessment of school-age children infected with maternally transmitted human immunodeficiency virus type 1 . The Journal of Pediatrics, v. 126, n.3, p. 375-379, 1995.

43. Papola, P., Alvarez, M., \& Cohen, H. 1994 Developmental and service needs of schoolaged children with human immunodeficiency virus infection: $A$ descriptive study. Pediatrics, 94(6), 914-918.). 
44. http://www.bibliotecadigital.ufmg.br/dspace/handle/1843/ECJS-84SGEV.

45. Benton, T.D. Psychiatric Considerations In Children And Adolescents With HIV/ aids. Child Adolesc Psychiatric Clin N Am, v.19, p. 387-400, 2010.

46. Christo, P. P.. (2010). Alterações cognitivas na infecção pelo HIV e Aids. Revista da Associação Médica Brasileira, 56(2), 242-247. Retrieved June 17, 2015, from http://www.scielo.br/scielo.php?script=sci arttext\&pid=S0104$42302010000200027 \& \operatorname{lng}=$ en\&tlng=pt.

47. Troncoso FT, Conterno LO. Prevalence of neurocognitive disorders and depression in a Brazilian HIV population. Rev Soc Bras Med Trop. 2015;48(4):390-8.

48. Heikinheimo T et al. Three-decade neurological and neurocognitive followup of HIV-1 infected patients on best-available antiretroviral therapy in Finland. BMJ Open. 2015;5(11):e007986.

49. Brew BJ, Chan P. Update on HIV dementia and HIV-associated neurocognitive disorders. Curr Neurol Neurosci Rep. 2014;14(8):468.).

50. Sacktor N, Lyles RH, Skolasky R, Kleeberger C, Selnes OA, Miller EN, et al. Multicenter AIDS Cohort Study. HIV-associated neurologic disease incidence changes: Multicenter AIDS Cohort Study, 1990-1998. Neurology 2001;56:257-60.

51. Neuenburg JK, Brodt HR, Herndier BG, Bickel M, Bacchetti P, Price RW, et al. HIV-1 related neuropathology, 1985 to 1999: rising prevalence of HIV encephalopathy in the era of highly active antiretroviral therapy. J Acquir Immune Defic Syndr. 2002;31:171-7.

52. Dilley JW, Schwarcz S, Loeb L, Hsu LNelson K, Scheer S. The decline of incidence cases of HIV-associated neurological disorders in San Francisco,1991-2003. AIDS. 2005;19:634-5 
53. Benton, T. D. (2011). Psychiatric considerations in child and adolescents with HIV/AIDS. Child and Adolescents Psychiatric Clinics of North America, 19(2), 989-1002.)

54. https://www.ncbi.nlm.nih.gov/pubmed/16777635

55. Nozyce ML, Lee SS,Wiznia A, et al. A behavioral and cognitive profile of clinically stable HIV-infected children.Pediatrics 2006;117:763-70.

56. Henrique, I.F., De Micheli, D.; De Lacerda, R.B; De Lacerda, L.A.; Formigoni, M.L. Validação da versão brasileira do teste de triagem do envolvimento com álcool, cigarro e outras substâncias (ASSIST). Rev Assoc Med Bras, 50:199-206, 2004. www. www.scielo.br/scielo.php?script=sci serial\&pid=0104-4230

57. Botega NJ et al. Transtornos do humor em enfermaria de clínica médica e validação de escala de medida (HAD) de ansiedade e depressão. Revista de Saúde Pública. 1995;29:359-63.)

58. Avaliação Neuropsicológica. [Online].; 2014. [cited 2017 January. Available from: http://www.aids.gov.br/pcdt/4.

59. Lawton MP, Brody EM. Assessment of older people: self-maintaining and instrumental activities of daily living. Gerontologist. 1969;9(3):179-86.),

60. Santos R L, Junior JSV. Confiabilidade da versão Brasileira da Escala de Atividades Instrumentais da Vida Diária. Brazilian Journal in Health Promotion. 2008;21(4):290-6

61. Avaliação Neuropsicológica. [Online].; 2014. [cited 2017 January. Available from: http://www.aids.gov.br/pcdt/4

62. Sacktor NC et al. The International HIV Dementia Scale: a new rapid screening test for HIV dementia. AIDS. 2005;19(13):1367-74). 
63. Ruff RM, Parker SB. Gender- and age-specific changes in motor speed and eye-hand coordination in adults: normative values for the Finger Tapping and Grooved Pegboard Tests. Percept Mot Skills. 1993;76(3 Pt 2):1219-30.)

64. Sacktor, N.C.; Wong, M.; Nakasujja.; N, et al. The international HIV-1 Dementia Scale: a new rapid screening test for HIV-1 dementia. aids, 19:136774, 2005. Recuperado em 13 de julho de 201.www.journals.Iww.com/aidsonline

65. Strauss E, Sherman E, Spreen O. A compendium of neuropsychological tests: Administration, norms, and commentary. 3 ed. New York: Oxford University Press; 2006.

66. Diniz, L.F.M.; Da Cruz, M.F.; Torres, V.M.; Cosenza, R.M. O teste de aprendizagem auditivo-verbal de Rey: nomas para uma população brasileira. Rev Bras Neurol, 36(3):79-83, 2000. Recuperado em 20 de julho de 2016.www. http://journalseek.net/cgi-

bin/journalseek/journalsearch.cgi?field=issn\&query=0101-8469.

67. Dancey CP, Reidy J. Estatística sem Matemática para Psicologia: usando SPSS para Windows. 3 ed. Porto Alegre: Artmed; 2006.

68. Saylor D, Dickens AM, Sacktor N, et al. HIV-associated neurocognitive disorder- pathogenesis and prospects for treatment. Nat Rev Neurol 2016;12:309.

69. Heaton RK, Clifford DB, Franklin DR Jr, et al. HIV-associated neurocognitive disorders persist in the era of potent antiretroviral therapy: CHARTER Study. Neurology 2010;75: 2087-96.

70. Rocha BA. Rastreio de transtornos neurocognitivos, depressão e ansiedade em pessoas com hiv/aids. S.n. ed. S.I.2011

71. Fernandes Filho SM, de Melo HR. Frequency and risk factors for HIVassociated neurocognitive disorder and depression in older individuals with HIV in northeastern Brazil. Int Psychogeriatr. 2012;24(10):1648-55 
72. Oliveira JF et al. Neurological disease in HIV-infected patients in the era of highly active antiretroviral treatment: a Brazilian experience. Rev Soc Bras Med Trop. 2006;39(2):146-51

73. Gascón MRP, Vidal JE, Mazzaro YM, Smid J, Marcusso RMN, Capitão CG, et al. Neuropsychological Assessment of 412 HIV-Infected Individuals in São Paulo, Brazil. AIDS Patient Care STDS. 2018;32:1-8.

74. Brasil, Ministério da Saúde. Manual Técnico para o Diagnóstico da Infecção pelo HIV. [Online].; 2016. [cited 2016 November. Available from: http://www.aids.gov.br/sites/default/files/anexos/publicacao/2013/55594/manual _tecnic o_hiv_2016_final_25_07_pdf_54115.pdf).

75. Macmillan C, Magder LS, Brouwers $P$, et al. Head growth and neurodevelopment of infants born to HIV-1-infected drug-using women. Neurology $2001 ; 57: 1402-1411$

76. Smith R, Wilkins M. Perinatally acquired HIV infection: long-term neuropsychological consequences and challenges ahead. Child Neuropsychol. 2015;21:234-68.

77. Van Rie A, Harrington PR, Dow A, Robertson K. Neurologic and neurodevelopmental manifestations of pediatric HIV/AIDS: a global perspective. Eur J Paediatr Neurol. 2007;11:1-9.

78. Zayyad Z, Spudich S. Neuropathogenesis of HIV: from initial neuroinvasion to HIV-associated neurocognitive disorder (HAND). Curr HIV/AIDS Rep. 2015;12:16-24.

79. Willen EJ. Neurovognitive outcomes in pediatric HIV. Ment Retard Dev Disabil Res Rev 2006;12:223-228.

80. Wilmshurst JM, Hammond CK, Donald K, Hoare J, Cohen K, Eley B. NeuroAIDS in children. Handb Clin Neurol. 2018;152:99-116. 
81. Shanbhag MC, Rutstein RM, Zaoutis T, Zhao H, Chao D, Radcliffe J.Neurocognitive functioning in pediatric human immunodeficiency virus infection: effects of combined therapy. Arch Pediatr Adolesc Med. 2005;159:651-6.

82. Vidal JE, Santos AMRD, Peixoto de Miranda ÉJF, Segurado AC. Long-term virologic and immunologic responses on darunavir/ritonavir - containing regimens among highly antiretroviral therapy-experienced patients: 7-year follow-up of a prospective cohort study in São Paulo, Brazil. Braz J Infect Dis. $2017 ; 21: 680-81$.

83. Domek GJ. Facing adolescentes and adulthood: the importance of mental health care in the global pediatric AIDS epidemic. J Dev Behav Pediatr 2009;30:147-50.

84. Antinori A et al. Updated research nosology for HIV-associated neurocognitive disorders. Neurology. 2007;69(18):1789-99

85. Clifford DB. HIV-associated neurocognitive disorder. Curr Opin Infect Dis. 2017;30:117-22.

86. Joska JA, Westgarth-Taylor J, Myer L, Hoare J, Thomas KG, Combrinck M, et al. Characterization of HIV-Associated Neurocognitive Disorders among individuals starting antiretroviral therapy in South Africa. AIDS Behav. 2011;15:1197-203.

87. Hoare J, Phillips N, Joska JA, Paul R, Donald KA, Stein DJ, et al. Applying the HIV-associated neurocognitive disorder diagnostic criteria to HIV-infected youth. Neurology. 2016;87:86-93.

88. European AIDS Clinical Society. Guidelines. Version 9.1 October 2018. Acessado em 25 de Novembro de 2018. Disponível em: http://www.eacsociety.org/files/2018_guidelines-9.1-english.pdf

89. Rodrigues RA, Oliveira RL, Grinsztejn B, Silva MT. Validity of the International HIV dementia scale in Brazil. Arq Neuropsiquiatr. 2013;71:376-9. 
90. Troncoso FT, Conterno LO. Prevalence of neurocognitive disorders and depression in a Brazilian HIV population. Rev Soc Bras Med Trop. 2015;48(4):390-8.

91. Sheppard DP et al. Random Number Generation in HIV Disease: Associations with Neuropsychological Functions and Activities of Daily Living. Arch Clin Neuropsychol. 2017;32(1):53-62.

92. Fernandes Filho SM, de Melo HR. Frequency and risk factors for HIVassociated neurocognitive disorder and depression in older individuals with HIV in northeastern Brazil. Int Psychogeriatr. 2012;24(10):1648-55.

93 Oliveira JF et al. Neurological disease in HIV-infected patients in the era of highly active antiretroviral treatment: a Brazilian experience. Rev Soc Bras Med Trop. 2006;39(2):146-51.).

94. Heikinheimo $T$ et al. Three-decade neurological and neurocognitive followup of HIV-1 infected patients on best-available antiretroviral therapy in Finland. BMJ Open. 2015;5(11):e007986.

95. Vassallo $\mathrm{M}$ et al. Virologically suppressed patients with asymptomatic and symptomatic HIV-associated neurocognitive disorders do not display the same pattern of immune activation. HIV Med. 2015;16(7):431-40.

96. Troncoso FT. Estudo da Prevalência de Alterações Neurocognitivas e Transtorno Depressivo em População Soropositiva para o HIV em Marília [Dissertação]. Faculdade de Medicina de Marília. [Online].; 2013 [cited 2016 November. Available from: http://www.famema.br/ensino/mestrado acade/mestrado dissertacoes.php

97. Brasil, Ministério da Saúde. Manual Técnico para o Diagnóstico da Infecção pelo HIV. [Online].; 2016. [cited 2016 November. Available from: http://www.aids.gov.br/sites/default/files/anexos/publicacao/2013/55594/manual _tecnic o_hiv_2016_final_25_07_pdf_54115.pdf. 
98. Tostes MA, Chalub M, Botega NJ (2004) The quality of life of HIVinfected women is associated with psychiatric morbidity. AIDS Care 16:177-186

99. Kremer H, Sonnenberg-Schwan U, Arendt G, Brockmeyer NH, Potthoff A, Ulmer A, et al. German Competence Network HIV/AIDS. HIV or HIV-therapy? Causal attributions of symptoms and their impact on treatment decisions among women and men with HIV. Eur J Med Res 14; 2009:139-46.

100. Penzac SR, Reddy S, Grimsley SR (2002) Depression in patients with HIV infection. Am J Health-Syst Pharm 57:376-386.

101. Almeida SM. Cognitive impairment and major depressive disorder in HIV infection and cerebrospinal fluid biomarkers. Arq Neuropsiquiatr. 2013;71(9B):689-92.

102. WHO. Depression and other common mental disorders. World Health Organization, Mental Health Research; 2017.

103. Boing AF, Melo GR, Boing AC, Moretti-Pires RO, Peres KG, Peres MA. Associação entre depressão e doenças crônicas: Um estudo populacional. Revista de Saúde Pública da Universidade de São Paulo. 2012;46.

104. Ismail Z, Elbayoumi H, Fischer CE, Hogam DB, Millikin CP, Schweizer, et al. Prevalence of Depression in Patients With Mild Cognitive Impairment: A Systematic Review and Meta-analysis. JAMA Psychiatry. 2017:58 - 67.

105. Seidl EMF, Tróccoli BT. Desenvolvimento de escala para avaliação do suporte social em HIV/aids. Psicologia: Teoria e Pesquisa. 2006;22:317-26

106. Kamat $\mathrm{R}$ et al. Incident major depressive episodes increase the severity and risk of apathy in HIV infection. J Affect Disord. 2015;175:475-80.).). 